\title{
Influence of current shear on Gymnodinium breve (Dinophyceae) population dynamics: a numerical study
}

\author{
Gang Liu, Gerald S. Janowitz*, Daniel Kamykowski
}

Department of Marine, Earth \& Atmospheric Sciences, North Carolina State University, Raleigh, North Carolina 27695-8208, USA

\begin{abstract}
A time-dependent, 2-dimensional population dynamics model which incorporates current shear has been developed based on a time-dependent, 1-dimensional population dynamics model reported in an earlier study. Vertical shear in the horizontal velocity is shown to influence the cross-shelf distribution of a 2-dimensional filament of Gymnodinium breve (Dinophyceae) cells, which alters position in the vertical due to environmentally acclimated diel vertical migration. Three different vertical nitrogen distribution patterns are considered in the simulations: a surface nutrient plume, a bottom nutrient plume, and a uniform concentration in the water column. The simulations demonstrate that $G$. breve's vertical migratory behavior tends to maintain population coherency despite the tendency of shear in the current to disperse the population, and that the shear can contribute to predictable cell cycling within the aggregation. The simulations also show that the vertical distribution pattern of the external nutrient source has significantly influenced the horizontal advection, dispersion and cellular attributes of a G. breve population using the modeled swimming rules.
\end{abstract}

KEY WORDS: Model · Dinoflagellate · Gymnodinium breve · Population dynamics · Behavior · Nutrients

Resale or republication not permitted without written consent of the publisher

\section{INTRODUCTION}

The dinoflagellate Gymnodinium breve, now Karenia brevis, has been studied for decades because it causes massive toxic red tides in the Gulf of Mexico. G. breve's capability for diel vertical migration has significant and fundamental effects not only in facilitating growth by allowing individual cells to seek nutrients vertically and/or to utilize solar irradiation at or near the surface (e.g. Dahl \& Tangen 1993, Kamykowski \& Yamazaki 1997), but also in influencing population spatial distribution, both in the vertical and horizontal directions (e.g. Franks \& Anderson 1992, Kamykowski et al. 1998a).

A dinoflagellate cell in situ is subjected to a range of physical processes occurring throughout a hierarchical spectrum of space and time scales (Mackas et al. 1985). Dinoflagellates swim with a range of speeds between 50 and $600 \mu \mathrm{m} \mathrm{s}^{-1}$ (Kamykowski \& McCollum 1986,

*Corresponding author. E-mail: janowitz@ncsu.edu
Levandowsky \& Kaneta 1987). The instantaneous rate of water motion always imposes a threshold on the range of planktonic swimming velocities (both direction and magnitude) beyond which the directed swimming of plankton is compromised (Kamykowski et al. 1998b). In the natural environment, Gymnodinium breve does not show any meaningful oriented swimming behavior in the horizontal direction, although it does conduct oriented vertical migration. Water motions may transport a $G$. breve population and may also accumulate or disperse $G$. breve cells in a population (Heil 1986, Franks \& Anderson 1992, Kamykowski et al. 1998b). However, the interaction between G. breve's vertical migration and the horizontal water motions may result in meaningful control on the depth that G. breve chooses based on changing environmental conditions encountered during transport. Therefore, the behavioral vertical migration must be considered in the context of ambient physical factors when investigating the in situ distribution of $G$. breve populations (Kamykowski 1974, Cullen \& Horrigan 1981). 
The Gymnodinium breve blooms usually start offshore in typically oligotrophic waters (cell numbers $<1000 \mathrm{l}^{-1}$ ) in the zone of initiation 18 to $74 \mathrm{~km}$ offshore of central Florida at depths of 12 to $40 \mathrm{~m}$ (Steidinger 1973, 1975, Steidinger \& Haddad 1981). The bloom can be transported shoreward depending on hydrological and meteorological conditions, largely influenced by winds and wind-induced upwelling or downwelling (e.g. Tester \& Steidinger 1997). Under appropriate hydrographic settings, the onshore and offshore transports associated with these coastal upwelling and downwelling events can induce the convergence of both seed populations and their required nutrients to initiate and support G. breve blooms. On the other hand, the dispersal of a bloom usually is induced by the breaking down of the physical concentrating mechanisms and/or by the change of the swimming behavior, rather than by decreased growth (Heil 1986).

In spite of the importance of the physical processes on the Gymnodinium breve population dynamics, especially on determining the $G$. breve harmful bloom dynamics, the extent to which biological mechanisms, including diel vertical migrations, combine with physical mechanisms to influence in situ G. breve distribution patterns is not well understood. This is due, in great extent, to the difficulty in simulating these biophysical interactions under laboratory conditions. Although some work has been done using in situ studies (e.g. Walsh et al. 1974, Blasco 1978) and computer modeling (Kamykowski 1995, 1997, Donaghay \& Osborn 1997, Frank 1997), a more intensive effort is required to understand the dynamics behind the west Florida $G$. breve red tides.

Among various types of water motions, vertical shear in horizontal water velocity is present everywhere in shelf and coastal regions due to wind and baroclinic effects, and is speculated to cause physical dispersion and even segregation of the cells in a Gymnodinium breve population (e.g. Kamykowski et al. 1998a). Without active vertical migration, the cells in the population are simply dispersed according to their vertical locations in the shear; however, the acclimation of G. breve's vertical migratory behavior to external environmental conditions may make the mechanisms of dispersion and segregation much more complicated. Hence, the vertical shear in the horizontal velocity is chosen as the object of this study.

This paper presents a new 2-dimensional Gymnodinium breve population dynamics model developed from the 1-dimensional $G$. breve population dynamics model introduced by Liu et al. (2001), hereinafter referred to as the LJK model. The 2-dimensional model simulates the horizontal evolution of a patch of G. breve cells, originally compacted in a region where a constant horizontal current is present with a simple linear vertical velocity shear, under 3 different nutrient conditions. The focus is the influence of the interaction among vertical velocity shear in the horizontal current, the ambient nutrient condition, and $G$. breve's nutrient-responsive vertical migratory behavior on the horizontal transport and dispersion of a $G$. breve population. In this paper, the structure of the new 2-dimensional model is introduced first, followed by the cases simulated by the model. Finally, the simulation results are presented and discussed, and conclusions are drawn from the numerical investigation.

\section{MODEL}

Description. A 2-dimensional Gymnodinium breve population dynamics model is developed from the 1-dimensional LJK model. Because the interest here is in the conceptual investigation of the influence of the vertical shear in a current on the G. breve population distribution and because the vertical shear itself is assumed to be time-independent, there is no need for fluid dynamics to be incorporated into the model. Thus, the 2-dimensional model is developed from the 1-dimensional LJK model by adding a horizontal spatial dimension without modifying any other part of the model. In this paper, only the new 2-dimensional part of the model is described. Readers are referred to Liu et al. (2001) for details of the remainder of the model.

The governing equation for the number of identical cells per unit volume in $x, z, C n, N, H_{C}, E_{3}$ space, $\underline{C}$, in our 2-dimensional model becomes:

$\frac{\partial \underline{C}}{\partial t}+\frac{\partial(u \underline{C})}{\partial x}+\frac{\partial\left(V_{z} \underline{C}\right)}{\partial z}+\frac{\partial\left(V_{C n} \underline{C}\right)}{\partial C n}+\frac{\partial\left(V_{N} \underline{C}\right)}{\partial N}+\frac{\partial\left(V_{H_{c}} \underline{C}\right)}{\partial H_{C}}+\frac{\partial\left(V_{E_{3}} \underline{C}\right)}{\partial E_{3}}$

$=$ Gains (reproduction)

Here, $u$ is the horizontal current velocity; $V_{z}$ is the cell swimming velocity; $C n, N, H_{C}$ and $E_{3}$ are the internal cellular states considered in the model and used as independent variables in addition to time $(t)$ and spatial location $(x, z)$. As in the LJK model, the independent variables are the internal cellular carbon (excluding the internal carbon in cellular protein), internal cellular nitrogen, extent of cumulative photoinhibition, and cellular sun-shade acclimation state (i.e. 3 d PAR exposure), respectively, besides time $(t)$, horizontal position $(x)$, and depth $(z)$. The second term on the left-hand side is the new horizontal advection term and was not present in the LJK model. In the present model, $z$ is positive upward with $z=0$ at the surface. The gain term on the right hand side is the rate of increase or decrease in cell number due to 
reproduction. It is assumed that there is no vertical water motion within the simulated water column. As in the LJK model, the effects of turbulence are neglected. The region of the Florida shelf considered here is frequently subject to low winds, and the water column is stably stratified. Both of these factors tend to lead to low turbulence levels. Thus, neglecting turbulence is a reasonable assumption for a model driven by baroclinically induced shear as considered here. The effects of turbulent mixing under simpler swimming rules for a generic dinoflagellate is discussed in Janowitz \& Kamykowski (1999). Except for the horizontal water velocity $u$, which is considered time-independent but depth-dependent in the present model and will be specified later, the other generalized velocities (i.e. $V_{z \prime}, V_{C n}, V_{N^{\prime}}, C_{H_{C^{\prime}}}$ and $V_{E_{3}}$ ) are the same specified functions of PAR, ambient nitrate concentration, internal carbon $(C n)$, internal nitrogen $(N)$, cumulative photoinhibition $\left(H_{C}\right)$, and sun-shade acclimation $\left(E_{3}\right)$ as in LJK. The rules for swimming behaviour $\left(V_{z}\right)$ depend on the time of day (4 periods are specified), scaled values of internal carbon and nitrogen, the cumulative inhibition, and values at depth of PAR, nitrate, and nitrate gradient. These rules are too complex to reproduce here and the reader is referred to Liu et al. (2001) for details.The upwind finite differencing scheme is applied to construct the model. Each independent field is subdivided into a finite number of intervals between its minimum and maximum values.

Simulations. The horizontal velocity in a water column can be decomposed into the sum of 2 velocity components: a vertically averaged mean velocity and an overlapping velocity shear. In our model, the spatial coordinate system follows the water column moving with the column's mean velocity which is set timeindependent; thus only the vertical expression of horizontal velocity shear is visible for an observer moving with this coordinate system. In the simulations, we assume a water column with a constant depth of $15 \mathrm{~m}$ and a constant, linear vertical velocity shear. The vertical profile of the horizontal velocity $\left(u ; \mathrm{m} \mathrm{s}^{-1}\right)$ with depth $(z ; \mathrm{m})$ relative to the moving coordinate system is given as:

$$
u(z)=0.01(1+z / 7.5)
$$

This velocity profile gives a relative velocity of $0.01 \mathrm{~m}$ $\mathrm{s}^{-1}$ at the surface, zero at mid-depth $(z=-7.5 \mathrm{~m})$, and $-0.01 \mathrm{~m} \mathrm{~s}^{-1}$ at the bottom $(z=-15.0 \mathrm{~m})$. Note that, in the model, $z$ is positive upward with $z=0$ at the sea surface. This velocity profile is consistent with a geostrophically balanced, vertically uniform, horizontal density gradient approximately related to a change of 1 salinity unit per $100 \mathrm{~km}$, characteristic of the study region.
As in the LJK model, nitrate is the only nutrient considered in the model and is used as a proxy for all nutrient sources. Three simple time-independent nitrate fields are specified to represent a surface nutrient plume, a bottom nutrient plume, and a vertically uniform water column. For the purpose of comparison between simulation results, the total amounts of nitrate in the water column of the 3 cases are the same and the vertical profile of the surface plume case is set as the mirror image to the profile of the bottom plume case (Fig. 1). The formulae of these 3 profiles with nitrate-nitrogen $\left(\mathrm{NO}_{3}-\mathrm{N}\right)$ in $\mu \mathrm{M}$ and depth $(\mathrm{z})$ in $\mathrm{m}$ are given next.

The vertical nitrate profile of the time-independent surface plume case (Fig. 1a) is

$\left[\mathrm{NO}_{3}(z)\right]_{\text {surface }}=0.1+0.01(15.0-z)+4.75(1+\tanh (5.0)) / 2.0$

where the first term is the background nitrate concentration on the west Florida shelf (see Lie et al. 2001 for details) and the second term produces an upward minimum vertical nitrate gradient of $0.01 \mu \mathrm{M} \mathrm{m} \mathrm{m}^{-1}$ which Gymnodinium breve can sense in its assumed chemotaxis (see the swimming submodel in Liu et al. 2001 for details). The maximum concentration is $5.0 \mu \mathrm{M}$ at the surface.

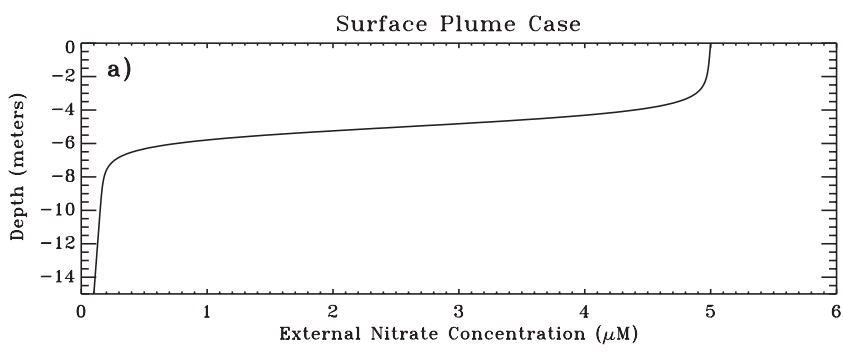

Bottom Plume Case
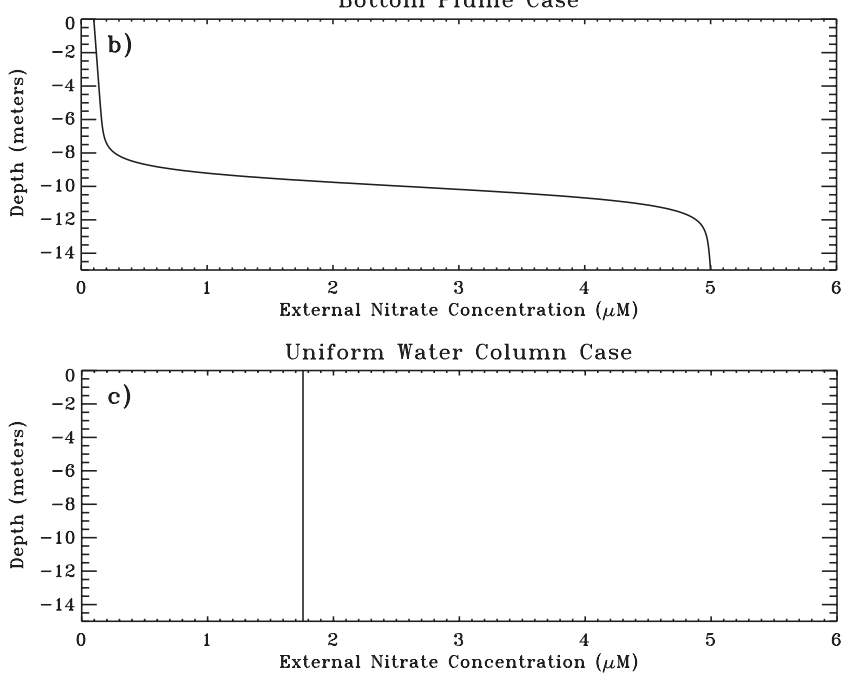

Fig. 1. Vertical nitrate profiles for 3 simulation cases. (a) Surface plume; (b) bottom plume; (c) uniform water column 
The vertical nitrate profile for the bottom plume case (Fig. 1b) is

$$
\left[\mathrm{NO}_{3}(z)\right]_{\text {bottom }}=0.1+0.01 z+4.75(1+\tanh (z-10.0)) / 2.0
$$

where the first term again is the background nitrate concentration on the west Florida shelf and the second term produces a downward vertical nitrate gradient of minimum $0.01 \mu \mathrm{M}$. The maximum NO3-N concentration is $5.0 \mu \mathrm{M}$ at the bottom.

The nitrate field for the uniform water column case (Fig. 1c) is:

$$
\left[\mathrm{NO}_{3}(z)\right]_{\text {background }}=1.758
$$

The uptake rate for the uniform water column is $80.7 \%$ of the potential maximum uptake rate throughout the column and the rates in the other 2 cases range between 19.2 and $92.3 \%$ of the potential maximum uptake rate. The difference between 80.7 and $92.3 \%$ is insignificant as far as the population growth is concerned. Note that nitrate concentration in the plumes and in the whole uniform water column can be greater than the $1.26 \mu \mathrm{M}$ threshold for stopping vertical migration (see the diel vertical migration model in Liu et al. 2001 for details).

All the model simulations were initiated at 03:00 h on the first day and ended at 06:00 $\mathrm{h}$ on the eleventh day with a total length of $10 \mathrm{~d}$. The $15 \mathrm{~m}$ water column is divided into 15 depth levels. In $10 \mathrm{~d}$, the maximum horizontal displacement of a water parcel staying at the surface and bottom, where the maximum current speeds of $0.01 \mathrm{~m} \mathrm{~s}^{-1}$ occur, is about $8.6 \mathrm{~km}$ from its initial location, and the separation of 2 water parcels, 1 staying at the surface and 1 at the bottom, is about $17.2 \mathrm{~km}$. A horizontal span of $20 \mathrm{~km}$ is thus chosen for the horizontal length of the model domain. In the model, the horizontal span of $20 \mathrm{~km}$ is divided equally into 21 intervals (or termed stations, with a station length of about $0.95 \mathrm{~km}$ ). The positive $x$-direction is chosen from lower station number to high station number in Figs. 3 to 9, from left to right. The cells in any horizontal interval (station) are considered to be distributed uniformly along the length of the interval. Note that discretization causes the water parcels in the surface and bottom levels, centered at -0.5 and $-14.5 \mathrm{~m}$ respectively, to move at the speed of $0.0093 \mathrm{~m}$ $\mathrm{s}^{-1}$, which is the maximum advective speed that can be obtained in the present vertical resolution.

In the simulations, all the cells are initially distributed uniformly, both horizontally and vertically, through the $15 \mathrm{~m}$ water column only in the 11 th interval (Stn 11), which is located at the middle of the domain. The initial cell concentration is 500 cells $\mathrm{l}^{-1}$, which is a background cell concentration on the west Florida shelf. All the initial cells are the new daughter cells of a quantized parent population with a division interval of $3 \mathrm{~d}$. All the other initial conditions, parameterizations, and the time step are the same as in the LJK model. The simulation results are given in the next section.

\section{RESULTS AND DISCUSSION}

\section{Simulation}

In this section, the simulation results of the 3 cases are presented and discussed with respect to the population development, vertical population distribution, and vertical distributions of the average internal cellular carbon and nitrogen concentrations, as in the LJK model. The emphasis here is on the difference in the spatial population distribution between cases; the respective vertical biochemical distributions are presented and discussed following the spatial population distribution in each case. The horizontal movement is relative to the model domain although the model domain itself moves with some vertically averaged velocity. The figures in this section are plotted using the hourly outputs of the model.

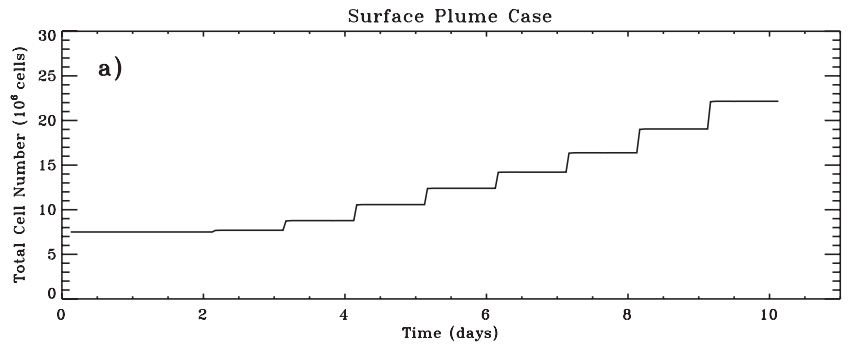

Bottom Plume Case
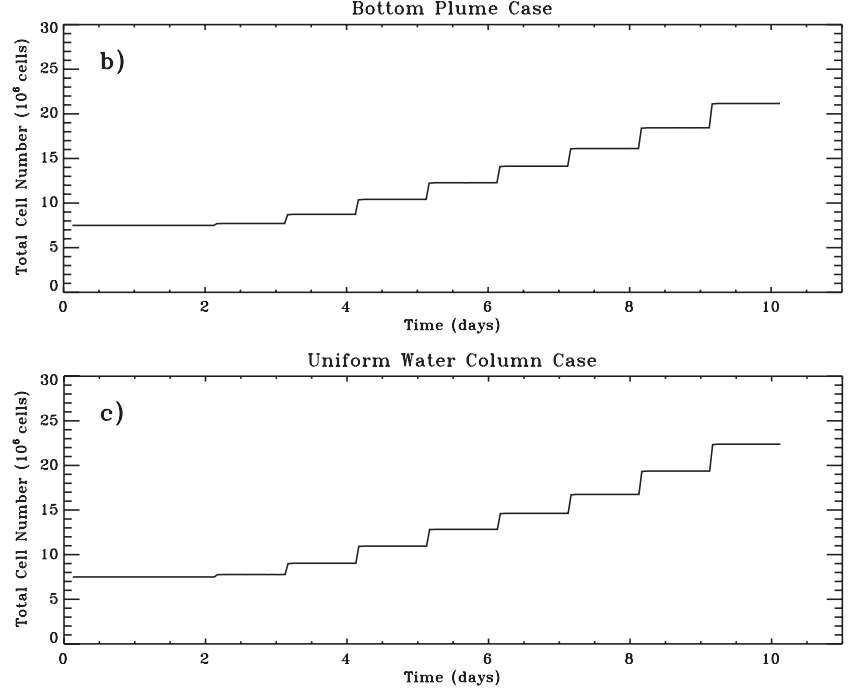

Fig. 2. Gymnodinium breve. Simulated population development for 3 simulation cases (Fig. 1) over $10 \mathrm{~d}$ period 
Population development over the $10 \mathrm{~d}$ period is shown in Fig. 2 for all 3 cases. The simulated population distribution in the $x-Z$ plane at noon (left graphs) and midnight (right graphs) every day over the course of the $10 \mathrm{~d}$ period is shown in Fig. 3 for all 3 cases. The simulated spatial distributions of the average internal carbon and nitrogen concentrations are shown in Fig. $4 \mathrm{a}$ and $\mathrm{b}$ respectively for the surface plume case,
Fig. 5a and $\mathrm{b}$ for the bottom plume case, and Fig. 6a and $b$ for the uniform water column case. In Figs. 3 to 6 , the white region contains no cells while the black region contains cells with cell concentration of less than 10 cells $\mathrm{l}^{-1}$. The cell concentration in the black region is too low to be considered significant and accurate because the numerical diffusion inherent in all numerical schemes may play a significant role in the (3a)
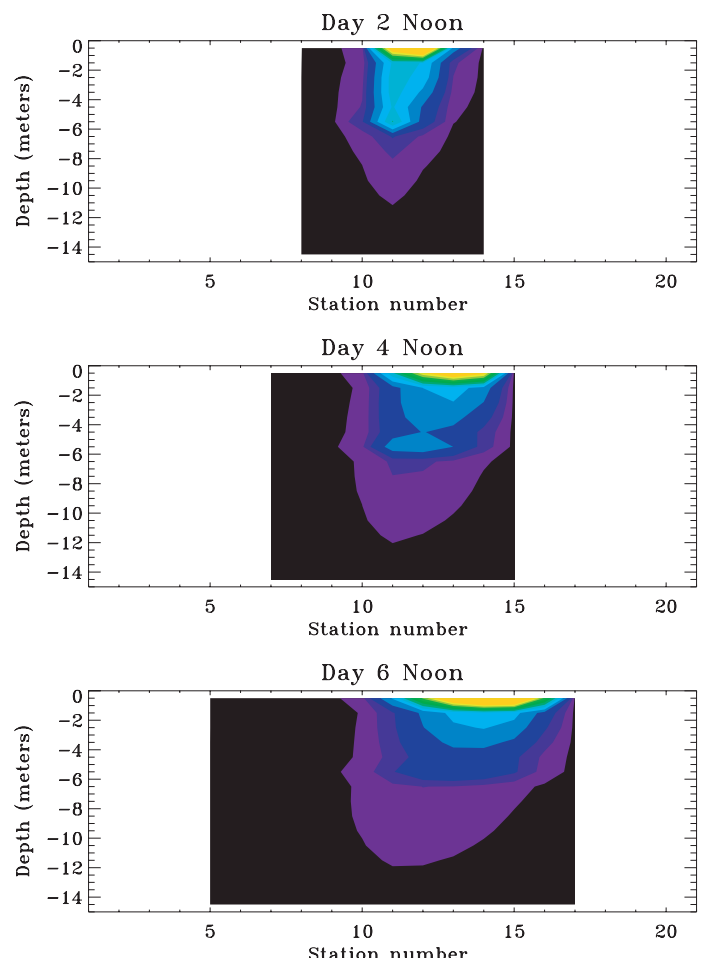

Day 8 Noon

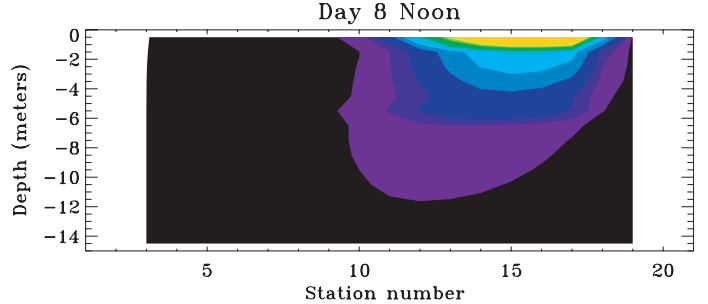

Day 10 Noon

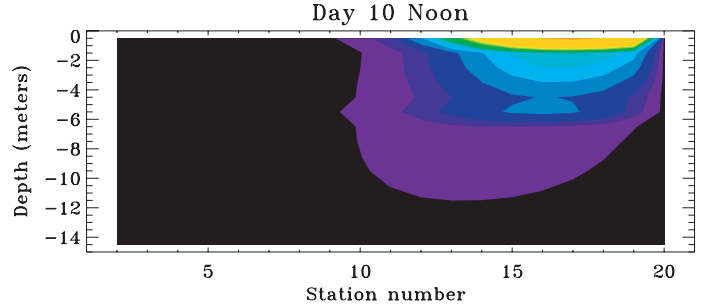

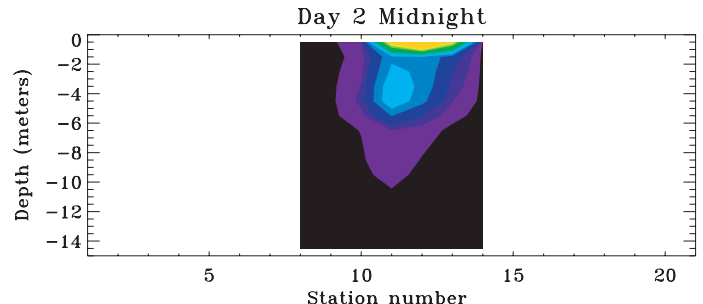
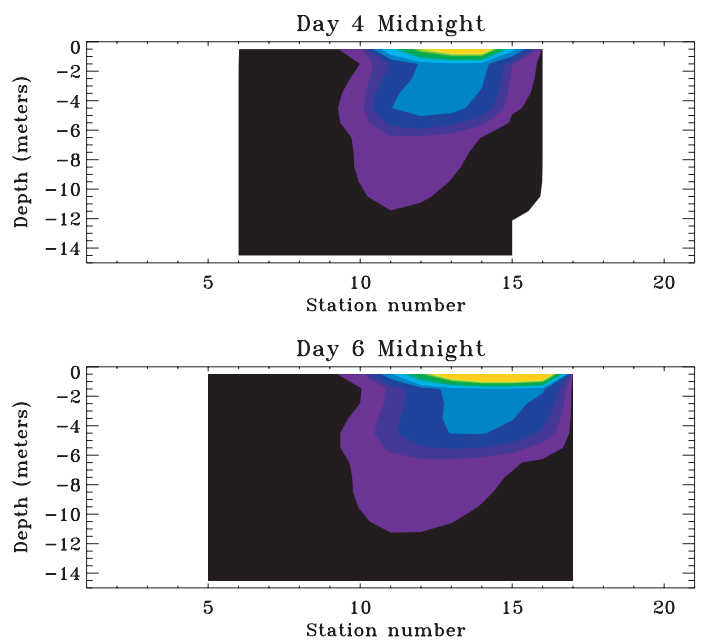

Day 8 Midnight

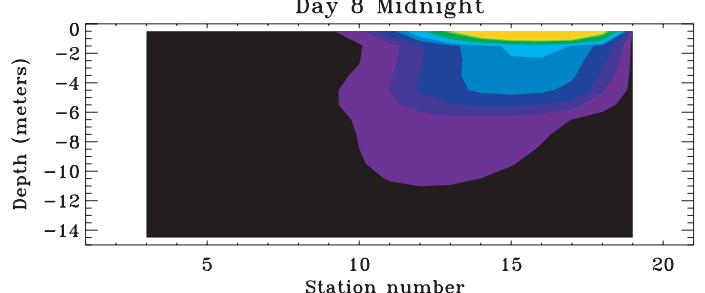

Day 10 Midnight

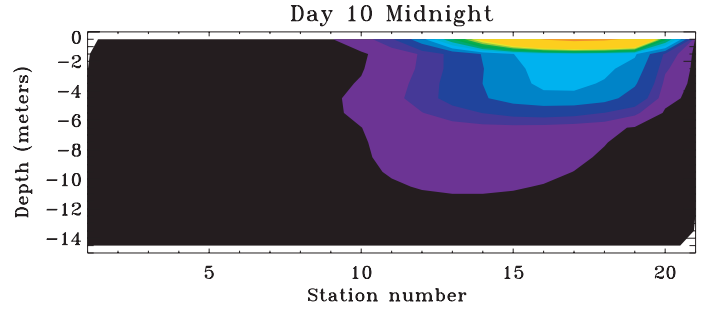

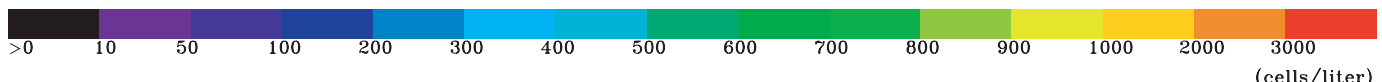

Fig. 3. Gymnodinium breve. Simulated population distribution in $x-z$ plane at noon and midnight on every other day during $10 \mathrm{~d}$ period in (a) surface plume (Fig. 1a), (b) bottom plume (Fig. 1b), and (c) uniform water column (Fig. 1c) 
(3b)
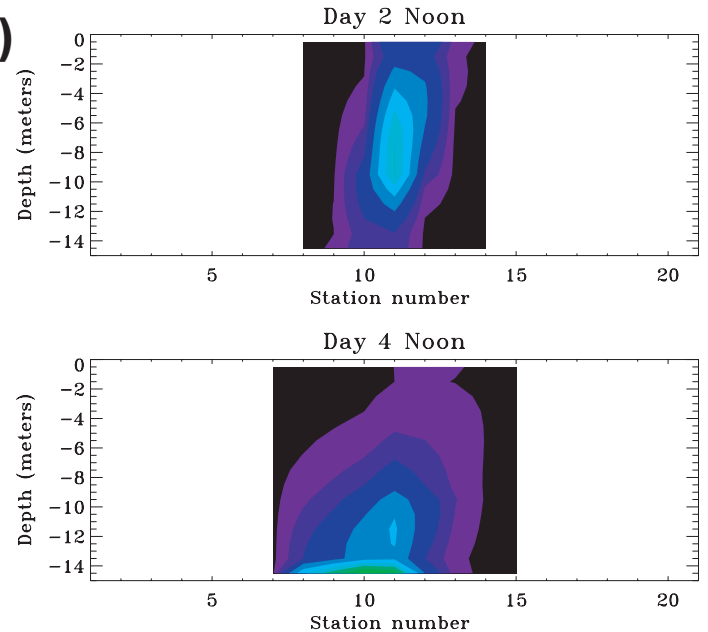

Day 6 Noon

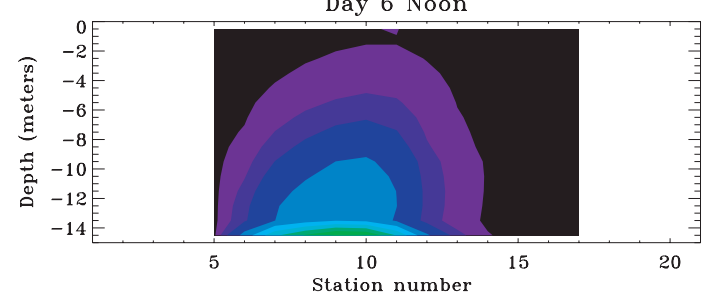

Day 8 Noon

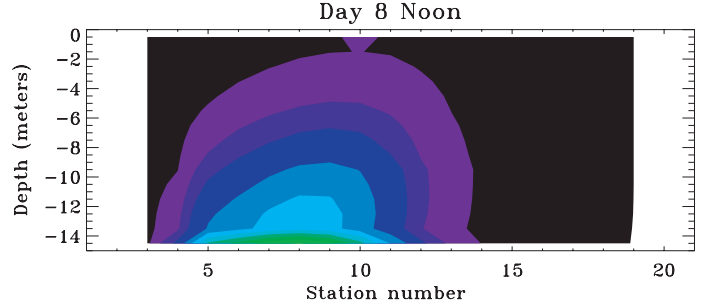

Day 10 Noon

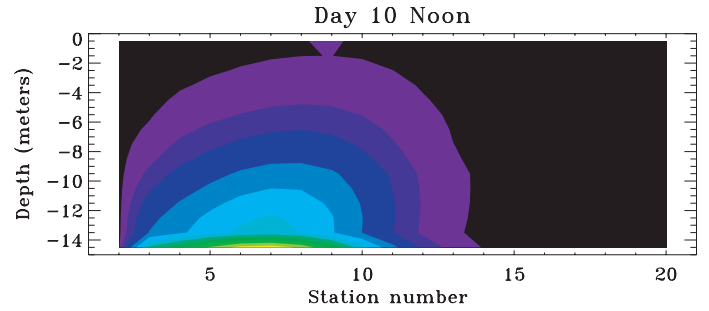

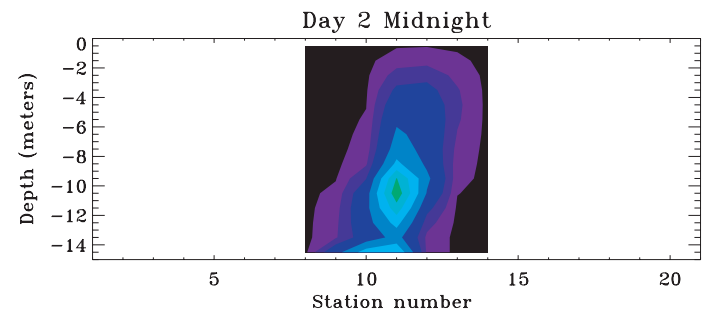

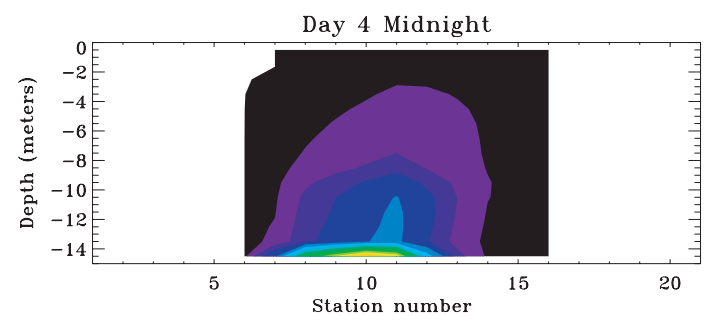

Day 6 Midnight

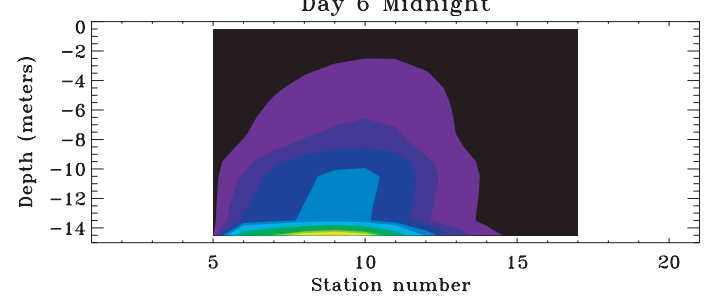

Day 8 Midnight

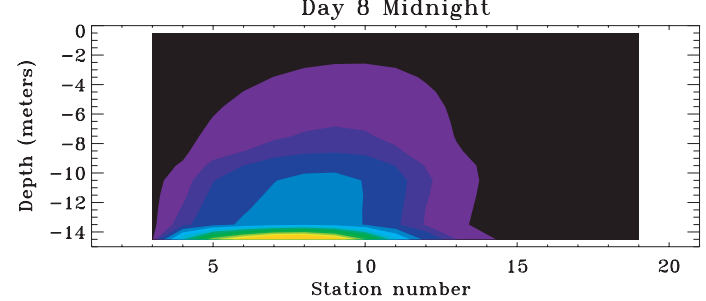

Day 10 Midnight

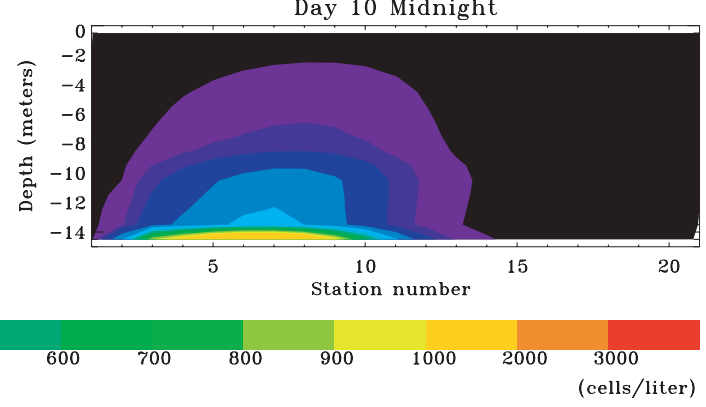

cell distribution in the region. As a result, the average internal cellular biochemical concentrations in the black region are not plotted in Figs. 4 to 6 . Note that the internal carbon and nitrogen concentrations in the vertical biochemical distribution figures (i.e. Figs. 4 to 6) are plotted on a per cell basis; high and low population density are given equal weight.

The difference in population size is very small between cases (Fig. 2), primarily because the total amount of the available nitrate in the water column is the same for all the cases and because the nitrate uptake rates in the plumes (where most of the cells in the populations aggregate in the 2 plume cases) and in the uniform water column are not very different. However, small differences in population size between the cases may be caused by the combined result of (1) the different vertical nitrate distribution patterns between cases, (2) the same light source with the intensity decreasing with depth for all 3 cases, and (3) the small differences in the extents of photoinhibition and self-shading effect between cases. The step-like shape of the curves in Fig. 2 is caused by the increase in the cell number in the population due to reproduction which occurs only between 03:00 and 06:00 h every day, with most of the 
(3c)

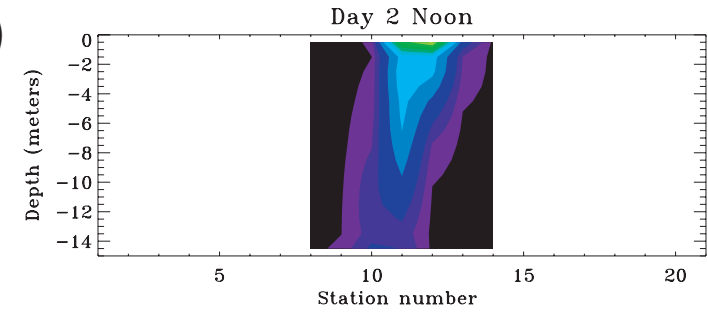

Day 4 Noon

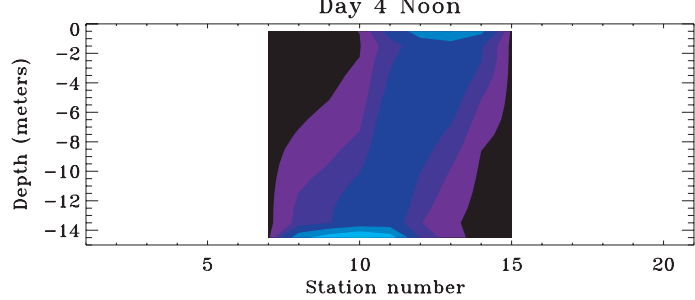

Day 6 Noon

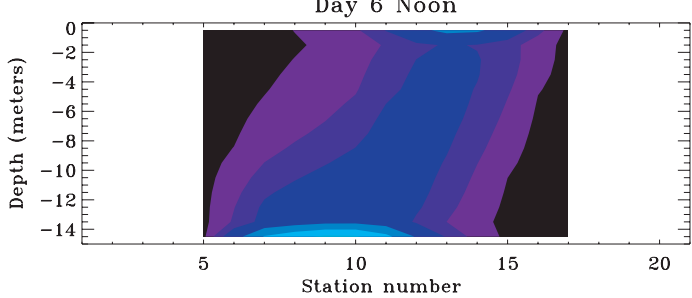

Day 8 Noon
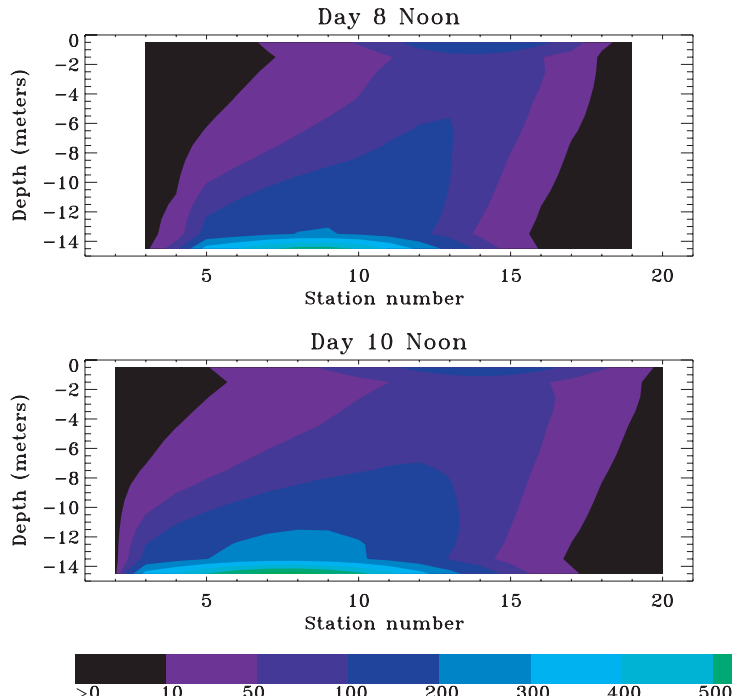
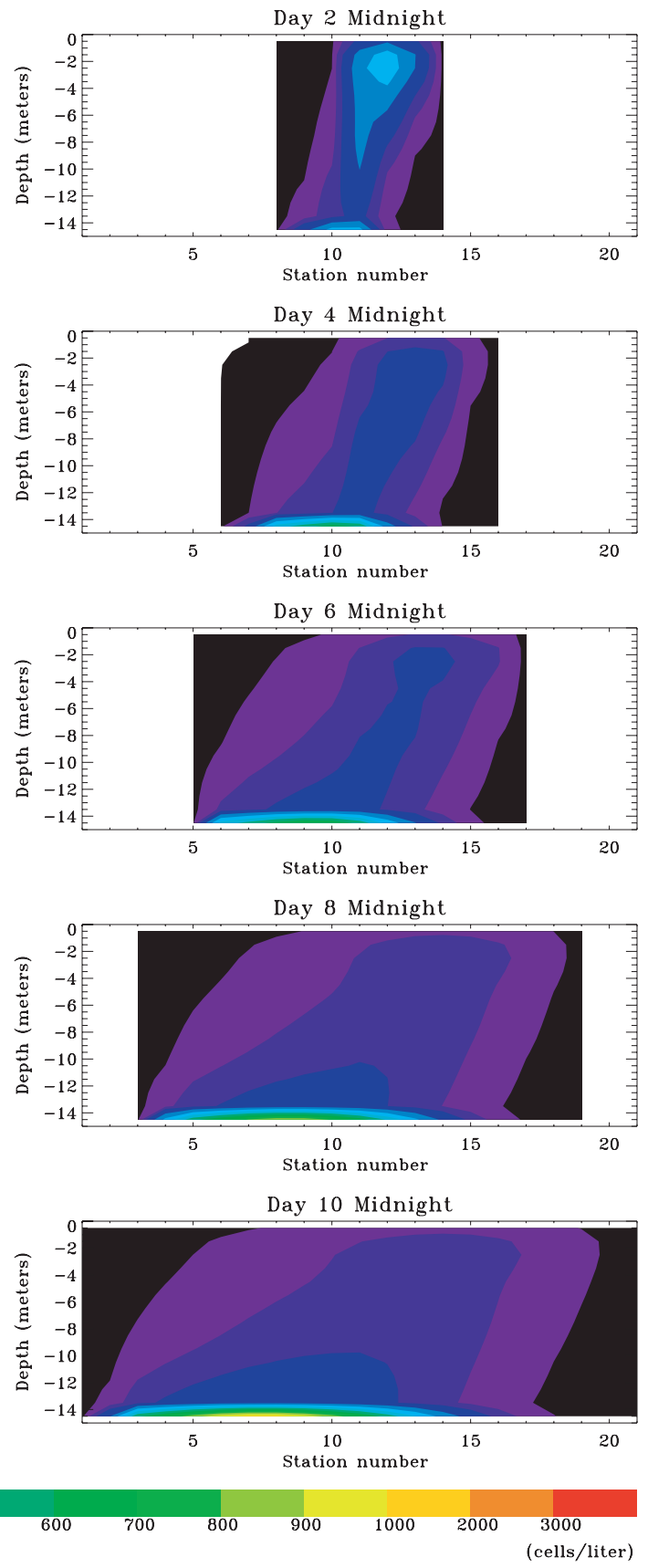

reproduction occurring around 03:00 h (see Liu et al. 2001 for details). As shown and discussed by Liu et al. (2001), the cell division starts $3 \mathrm{~d}$ after the initial time.

Although population development over the $10 \mathrm{~d}$ period is almost the same for all 3 cases, the spatial population distribution and biochemical distributions vary dramatically between cases (Figs. 3 to 6). As shown and explained in Liu et al. (2001), the population takes about $3 \mathrm{~d}$ to 'spin up' from the more or less arbitrary initial conditions in each case. After the spinup period, the spatial population distribution (Fig. 3) primarily responds to the vertical nitrate distribution and vertical velocity shear. In the surface plume case, the population aggregates strongly at the surface and weakly at the base of the plume. In the bottom plume case, cells aggregate at the bottom. In the uniform water column case, cells aggregate strongly at the bottom and weakly near the surface. Hence, depending on the depth of the population aggregation, the population is advected to the right in the surface plume case, and to the left in both the bottom plume and uniform water column case.

To illustrate more clearly the development of the vertical population distribution, the cell concentra- 
(4a)

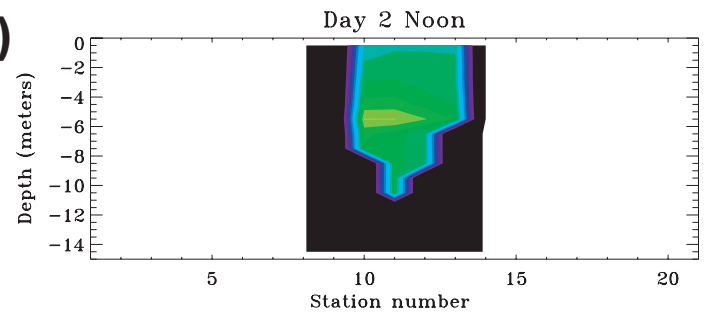

Day 4 Noon

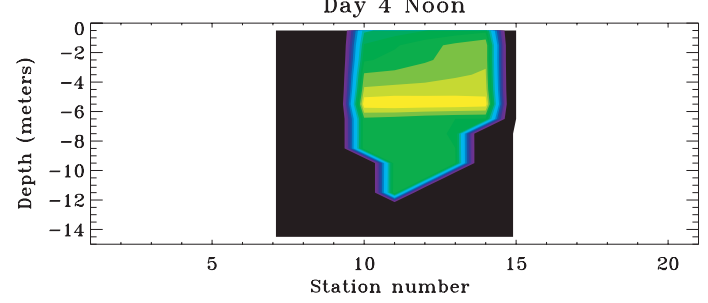

Day 6 Noon

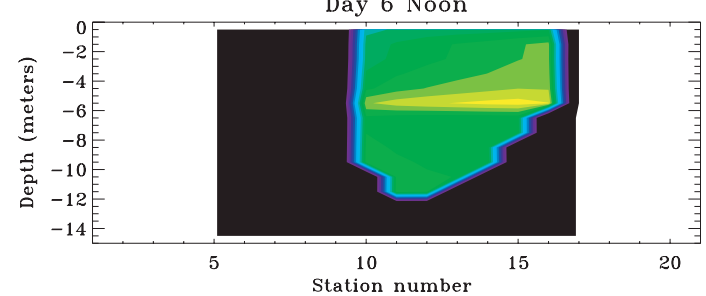

Day 8 Noon
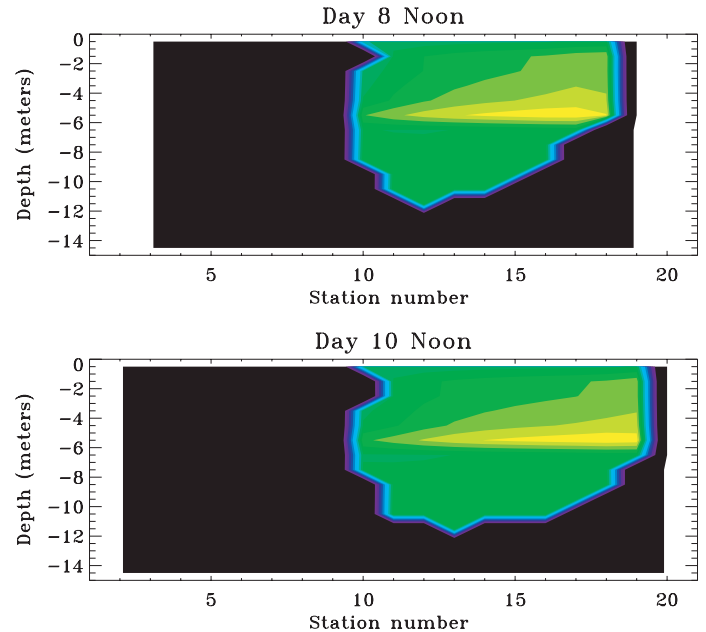

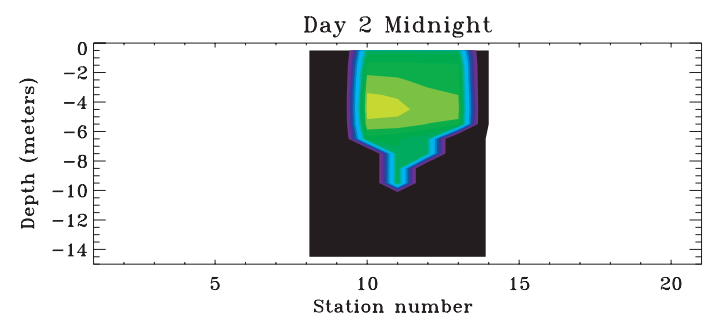

Day 4 Midnight

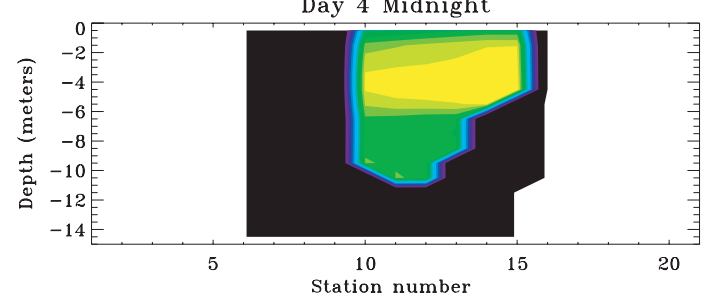

Day 6 Midnight

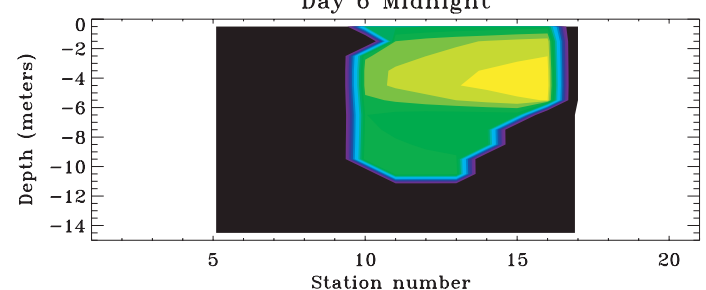

Day 8 Midnight

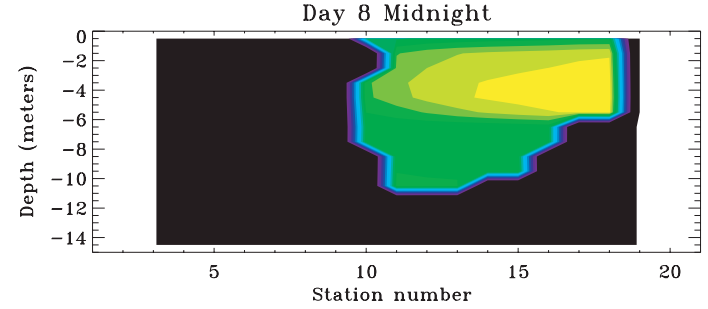

Day 10 Midnight

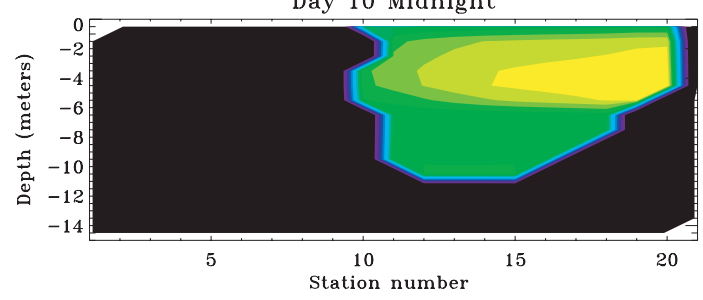

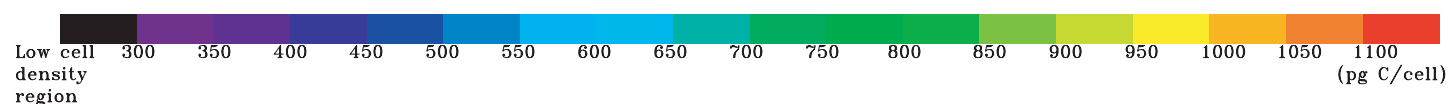

Fig. 4. Gymnodinium breve. Simulated distribution of average internal cellular carbon (a) and nitrogen (b) concentration in $x-Z$ plane at noon and midnight on every other day during $10 \mathrm{~d}$ period in surface plume. Cell concentration in black region is $<10$ cells $^{-1}$, i.e. insignificant for the purposes of our analysis, and white region contained no cells

tions over all the stations at each depth level are summed and the resultant vertical population distribution over the $10 \mathrm{~d}$ period is given in Fig. 7 for the 3 cases. As discussed above, the difference in the vertical population distribution between the cases is primarily caused by the difference in the vertical nitrate distribution.
To reveal whether the horizontal dispersion caused by the vertical velocity shear plays significant roles in the horizontally averaged vertical population distribution and population development, 1-dimensional simulations (not shown) without the vertical velocity shear were conducted for all 3 cases; the simulation results exhibit vertical population distributions that are almost 
(4b)
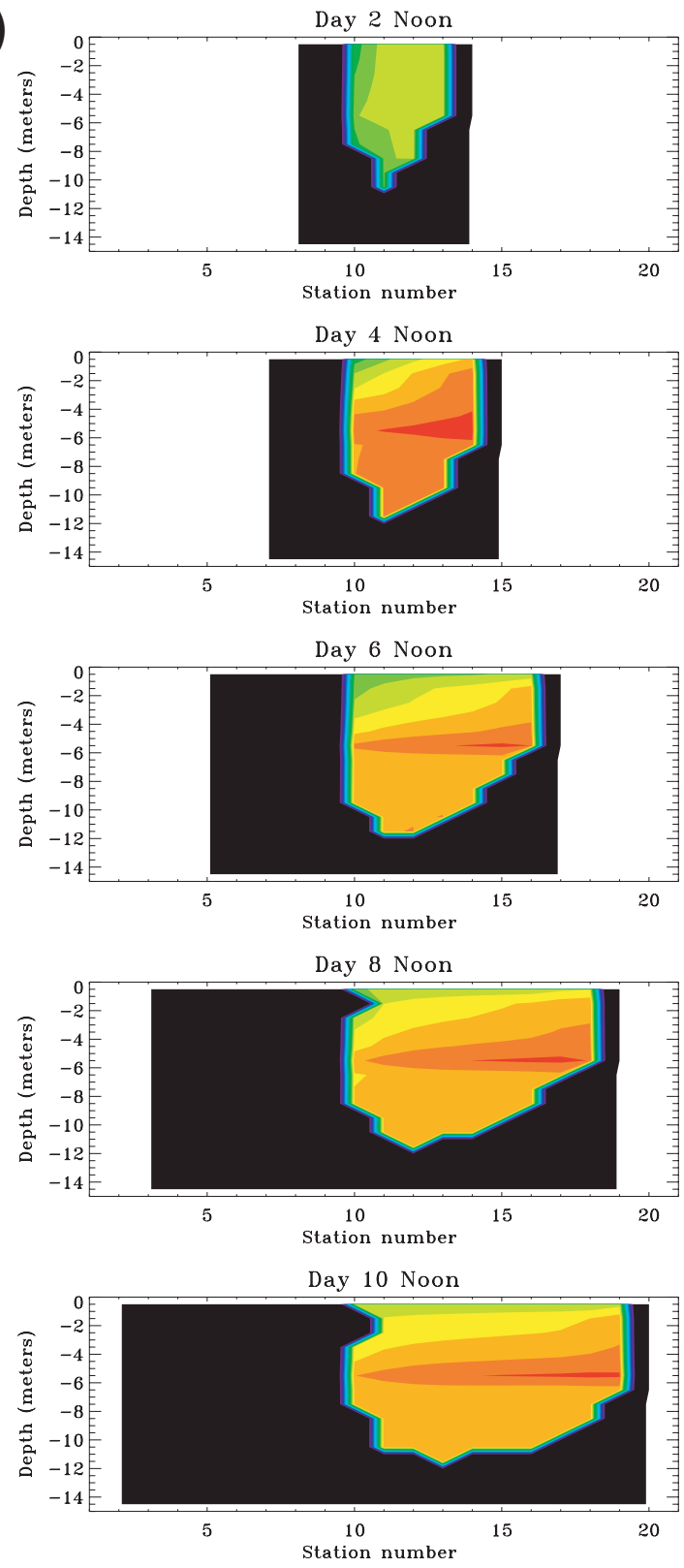
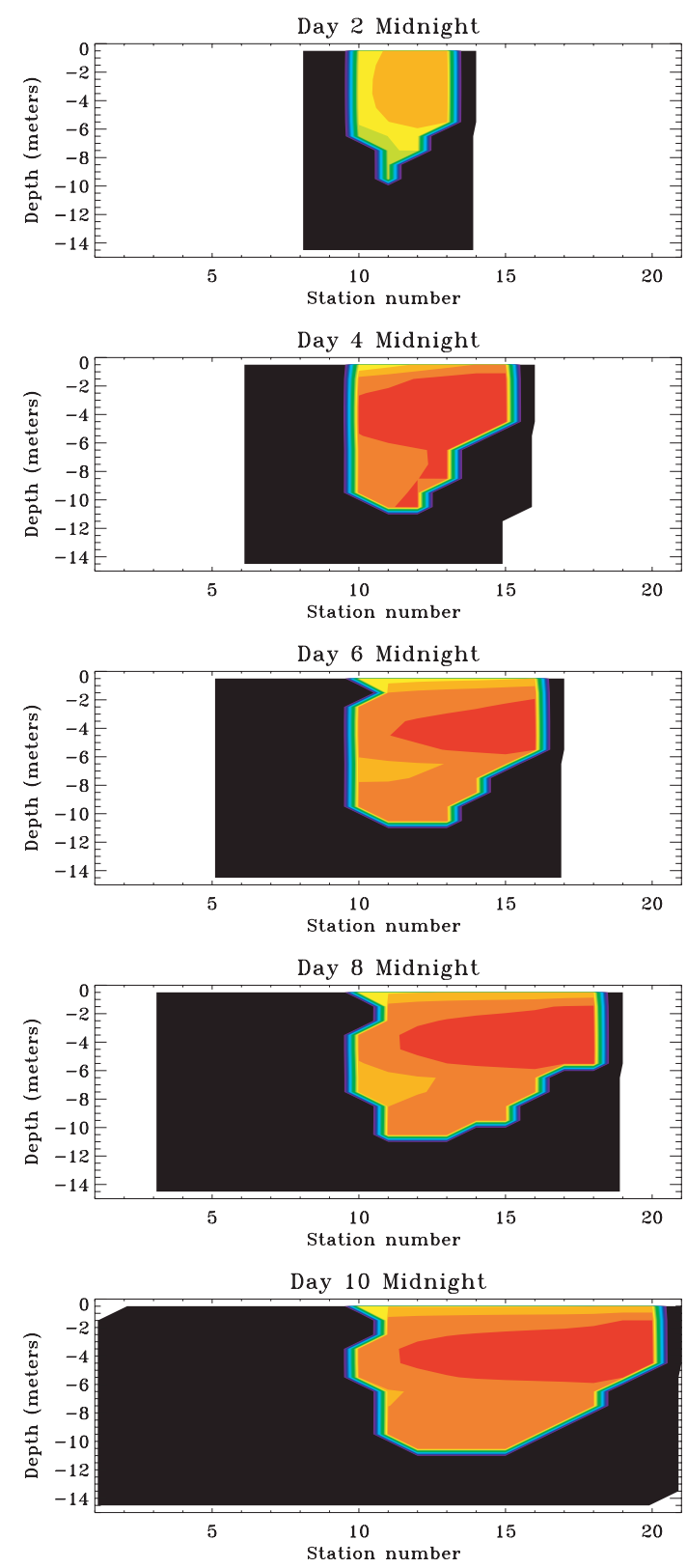

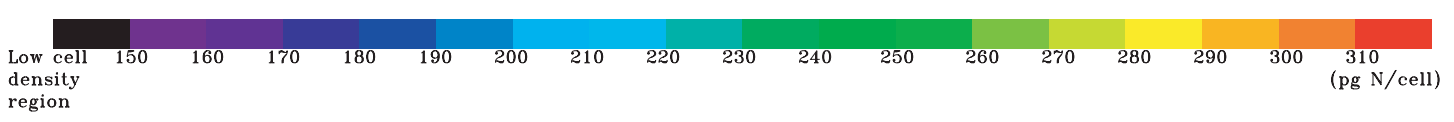

identical to the associated 2-dimensional simulations as shown in Fig. 7. The simulated population sizes in the 1-dimensional simulations are only slightly larger than the respective 2-dimensional simulations, with the difference less than $0.5 \%$ at the end of the $10 \mathrm{~d}$ period. The small difference may be caused by the stronger photoinhibition in the 2-dimensional cases where the horizontal population dispersion keeps reducing the self-shading effect over the course of the $10 \mathrm{~d}$ period. Consequently the cells are continuously exposed to higher light intensities than the intensities to which they have been adapted. Higher photoinhibition decreases their photosynthetic rates. Because of the low cell concentration in the simulations, the selfshading effect and thus the decrease in the photosynthetic rate are not significant. Hence, in our $10 \mathrm{~d}$ simulations, the vertical velocity shear does not have significant influence on the horizontally averaged vertical population distribution. To further demonstrate this self-shading effect, both 1- and 2-dimensional simulations were conducted for a higher initial cell concentration of 50000 cells $1^{-1}$. The expected larger 
(5a)

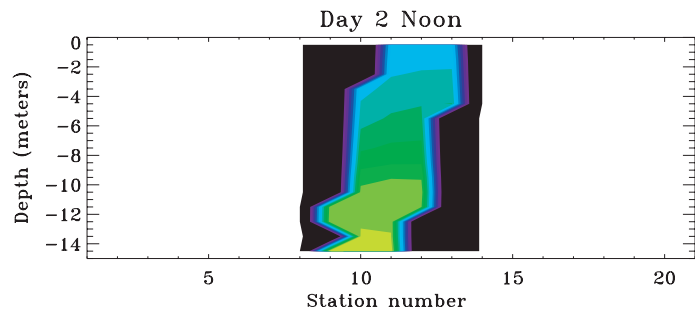

Day 4 Noon

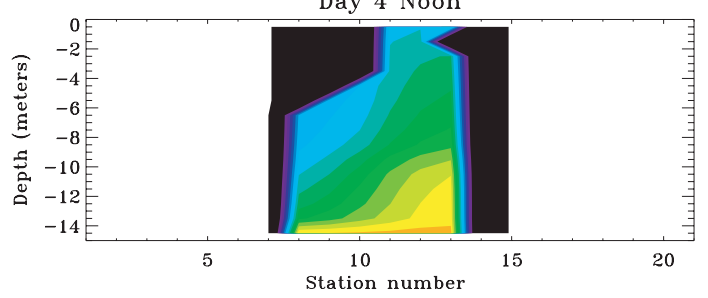

Day 6 Noon

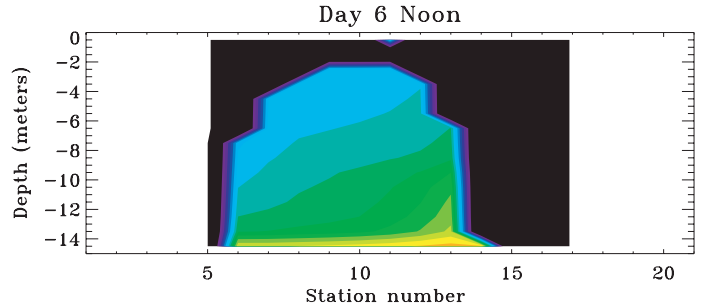

Day 8 Noon
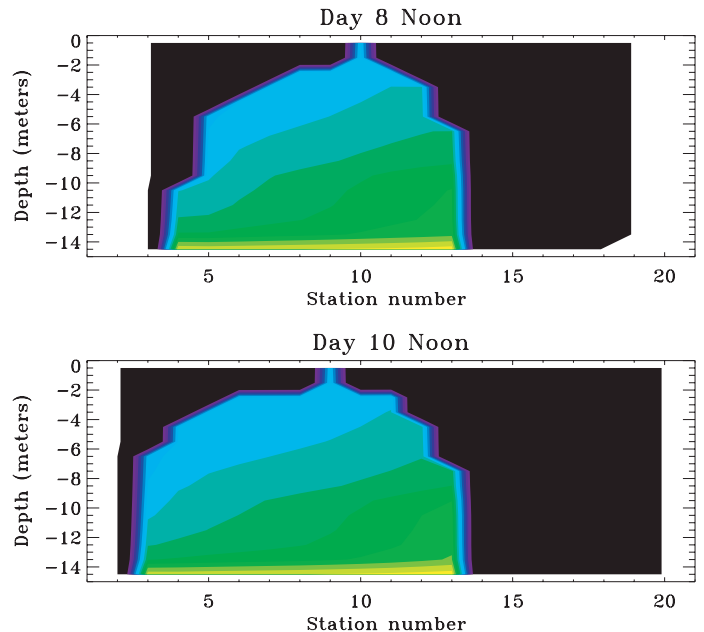

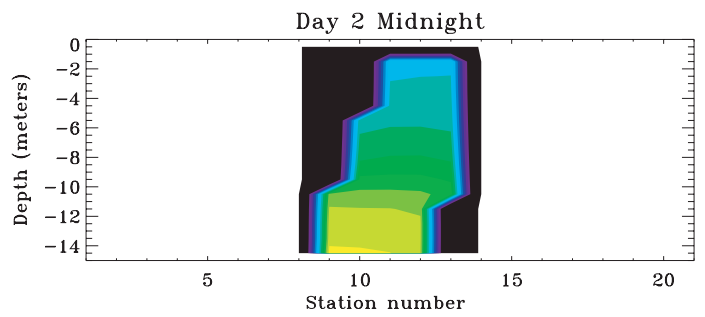

Day 4 Midnight

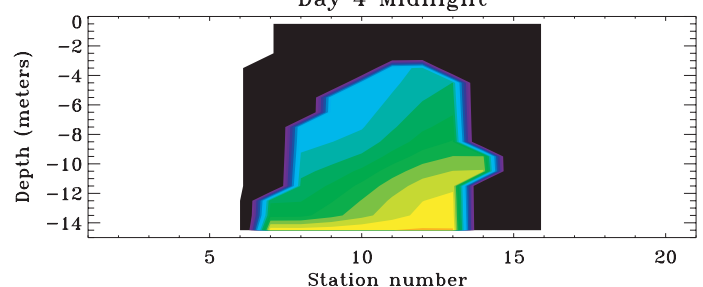

Day 6 Midnight

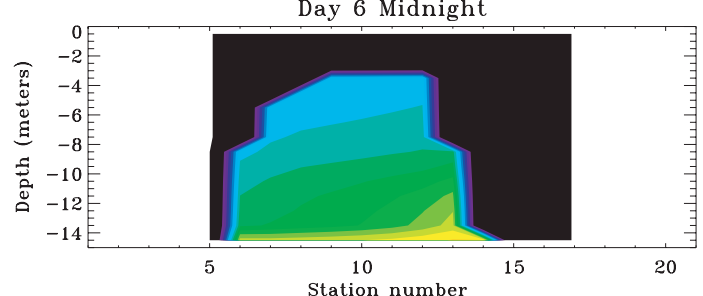

Day 8 Midnight

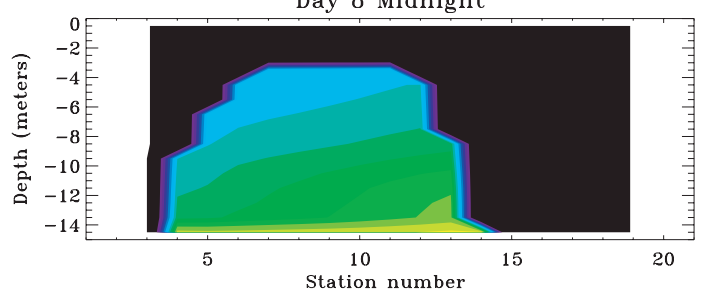

Day 10 Midnight

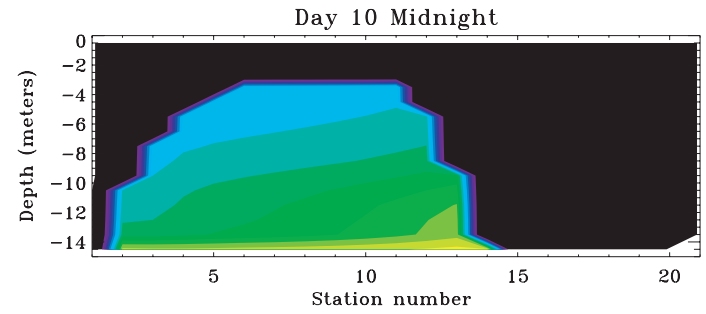

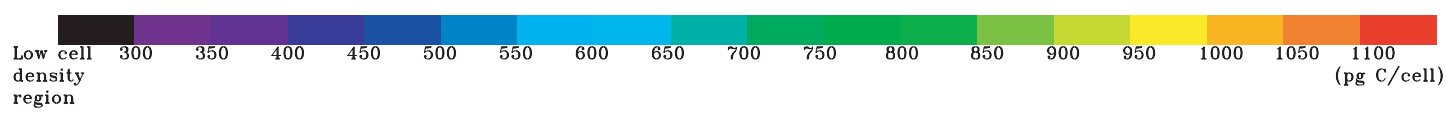

Fig. 5. Gymnodinium breve. Simulated distribution of average internal cellular carbon (a) and nitrogen (b) concentration in $x-Z$ plane at noon and midnight on every other day during $10 \mathrm{~d}$ period in bottom plume. Further details as in Fig. 4 legend

difference in population size between the 1- and 2-dimensional simulations resulted. Next, we move to the individual cases. In the surface plume case during the day, low-carbon cells in the population aggregate at the surface with higher light intensity (Figs. 3a \& 4a). Because the nitrate concentration above the base of the plume is greater than the $1.26 \mu \mathrm{M}$ threshold for stopping vertical migration during certain periods (see Liu et al. 2001 for details), the high-carbon cells descend and aggregate at the base of the plume during the day (Fig. 4a). However, the slow descending speeds of high-carbon cells in high nitrate concentration regions cause many of them to spend some time at or near the surface and many of them to spread over the depth range of the plume. Due to the high nitrate concentration in the plume, the cells aggregating at the 
(5b)

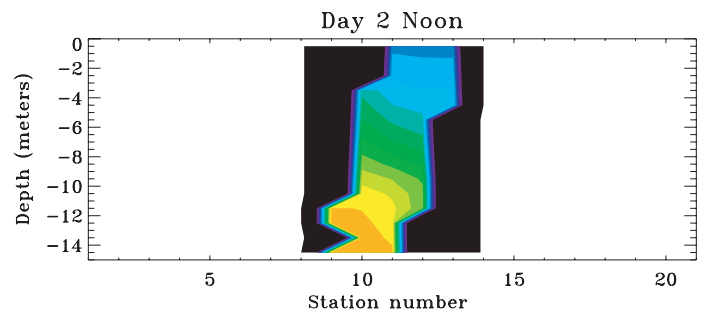

Day 4 Noon

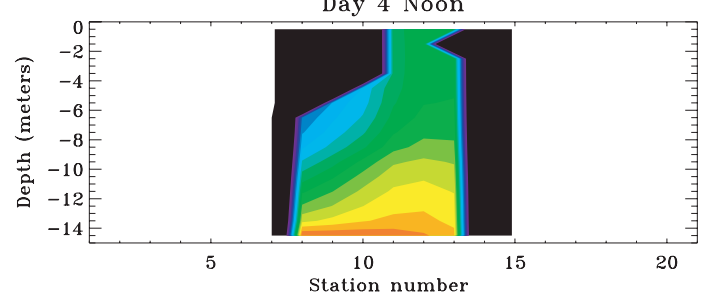

Day 6 Noon
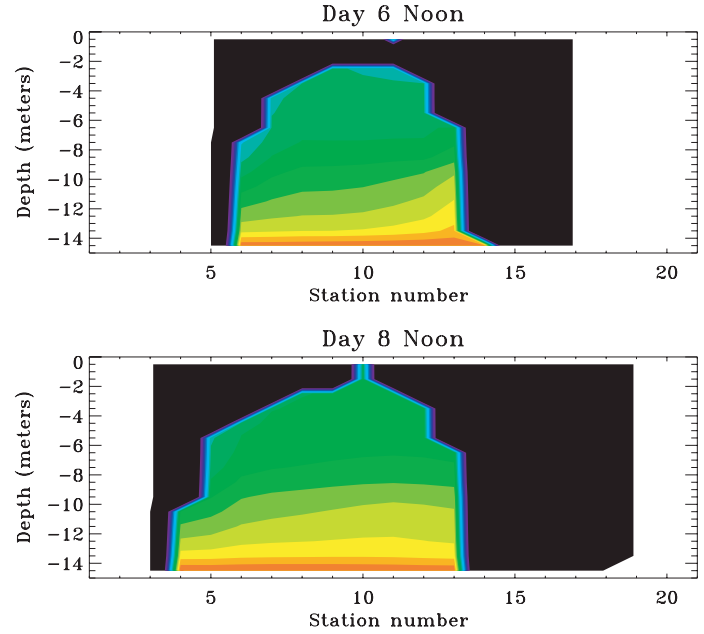

Day 10 Noon

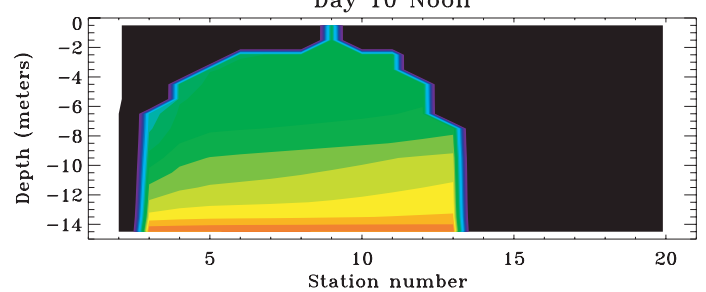

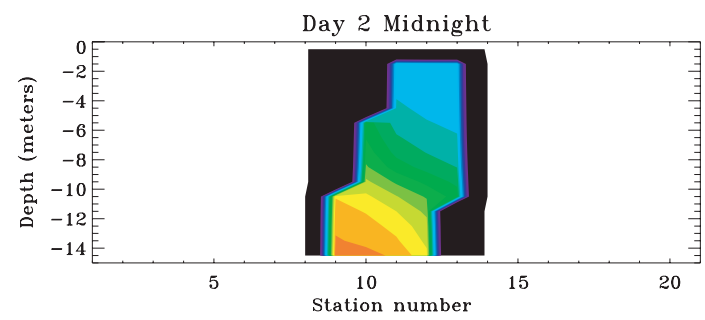

Day 4 Midnight

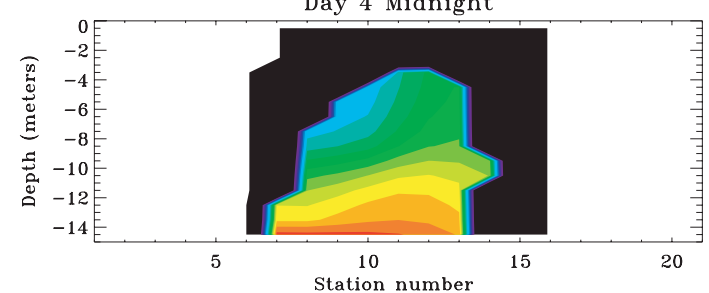

Day 6 Midnight

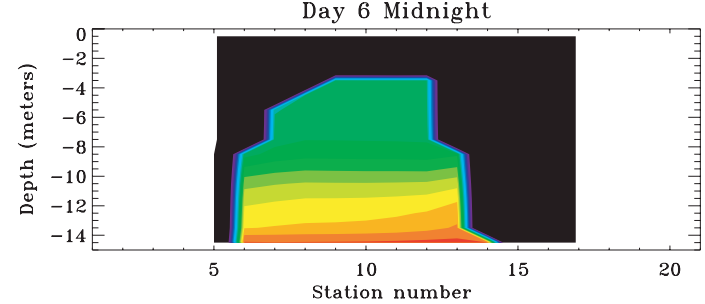

Day 8 Midnight

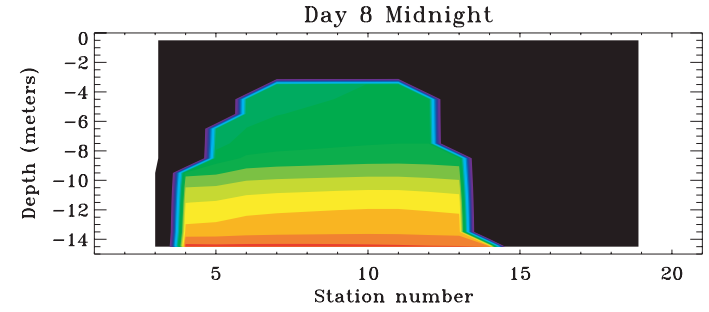

Day 10 Midnight

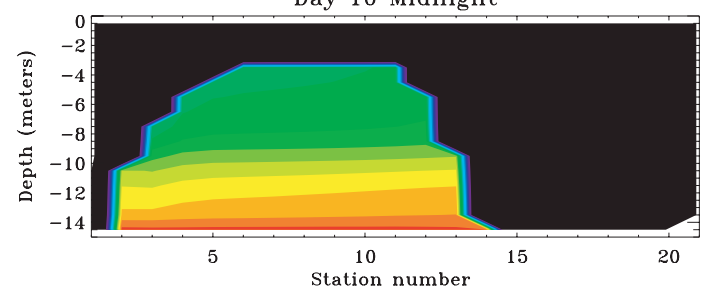

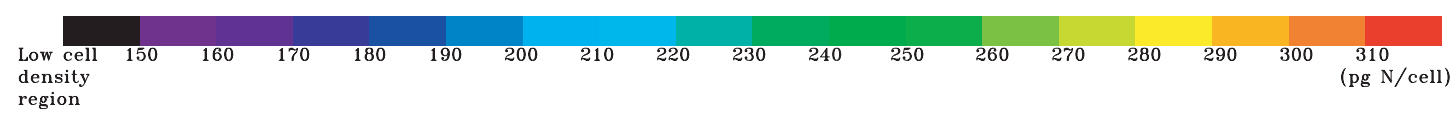

surface are mostly new or young daughter cells with low nitrogen concentrations, and the cells aggregating at the base of the plume are high-nitrogen cells (Fig. 4b), as expected. The cells in present very low cell concentrations below the plume depth during the day, as seen more easily in Fig. $7 \mathrm{a}$, may be either the cells recently forced down by photoinhibition or the products of numerical diffusion.

At night, between sunset and midnight, our swimming rules orient the nitrogen-seeking cells to the surface in the plume because the vertical nitrate gra- dient is upward and greater than $0.01 \mu \mathrm{M} \mathrm{NO}_{3}-\mathrm{N} \mathrm{m}^{-1}$ in magnitude. This ascent reinforces the surface aggregation already formed during the day. Between midnight and $2 \mathrm{~h}$ prior to sunrise, the nitrate-seeking induced ascent stops for the cells above the base of the plume where the nitrate concentration is greater than $1.26 \mu \mathrm{M}$. Cells below the base continue to ascend until reaching and aggregating at the base of the plume or time runs out. As a result, the surface cell concentration increases over the night. This variation in the vertical cell distribution over time is de- 
(6a)
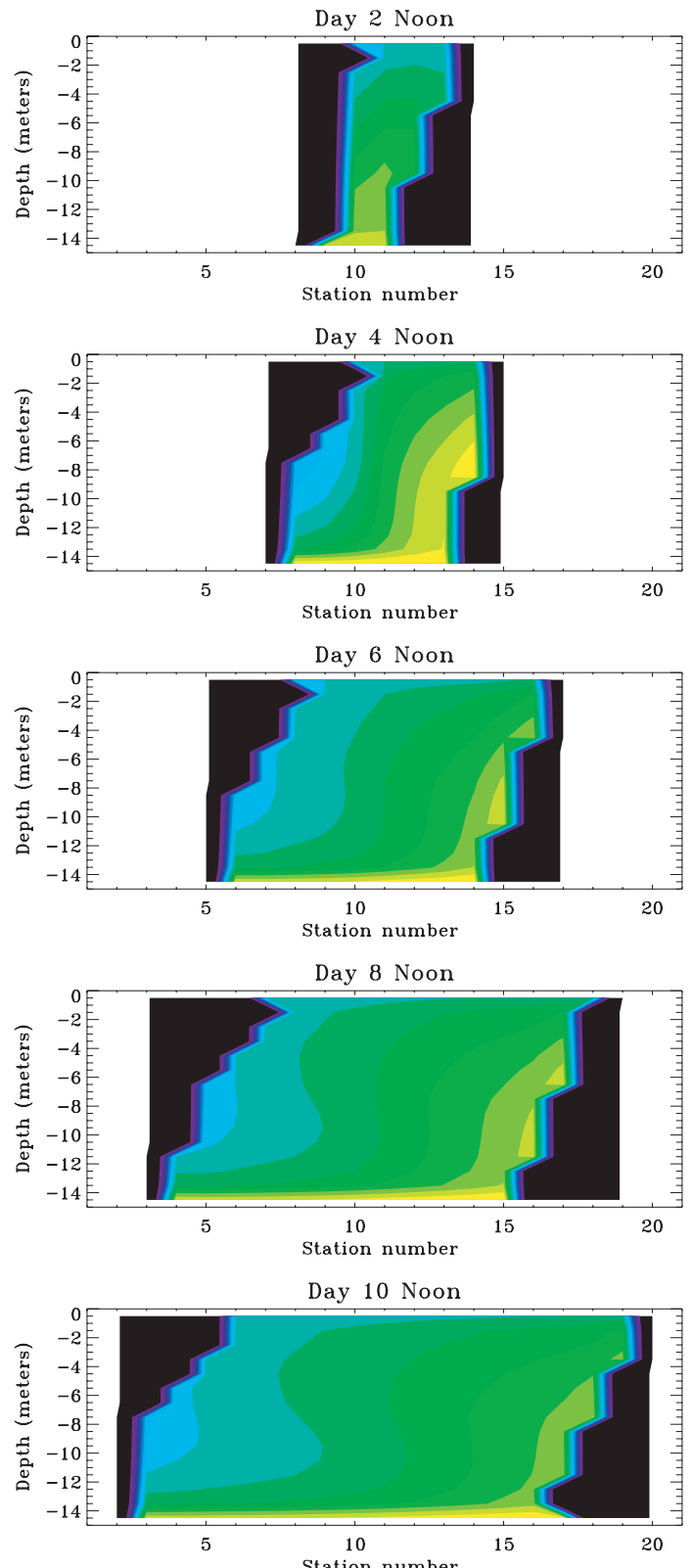

Station number
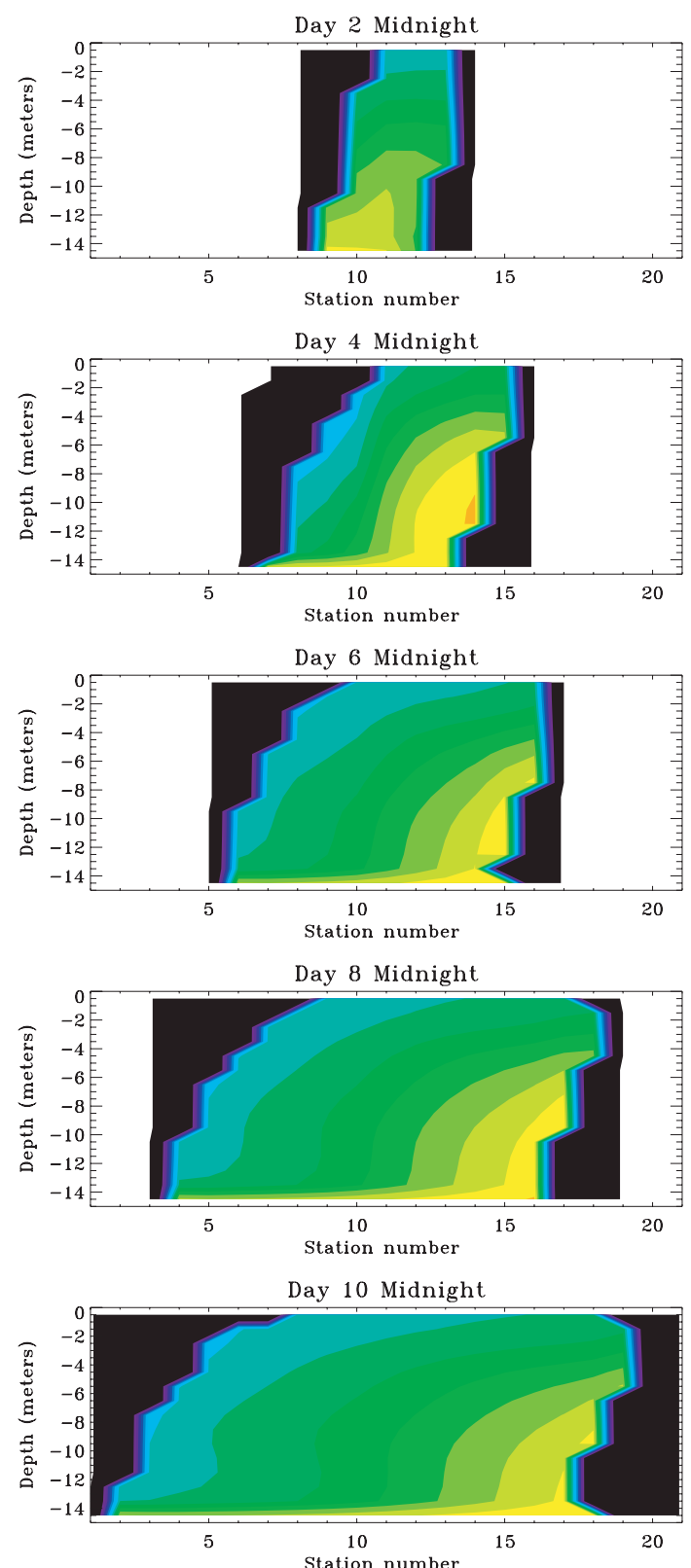

Station number

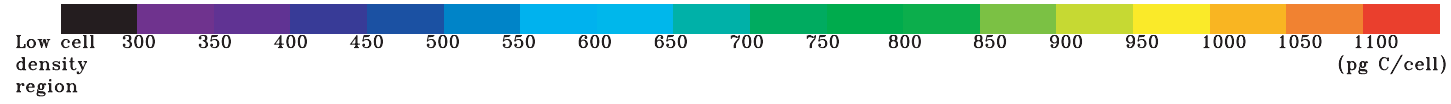

Fig. 6. Gymnodinium breve. Simulated distribution of average internal cellular carbon (a) and nitrogen (b) concentration in $x-Z$ plane at noon and midnight on every other day during $10 \mathrm{~d}$ period for uniform water column. Further details as in Fig. 4 legend

monstrated clearly in Fig. 7. The daily maximum surface cell concentration occurs around 09:00 h because of to the ascent of the low-carbon cells, mostly the new daughter cells produced in the reproduction period between 03:00 and 06:00 $\mathrm{h}$. The decrease in the surface cell concentration between 09:00 $\mathrm{h}$ and sunset is due to more cells descending from the surface. A more detailed explanation for the vertical pop- ulation distribution in a similar vertical nitrate distribution condition, i.e. the coastal surface plume, can be found in Liu et al. (2001).

As stated by Liu et al. (2001), the simulated strong surface aggregation at night in this case may not be generally realistic, although strong surface aggregation has been observed in natural blooms during the dark period (Heil 1986). This may also be true for the simu- 
(6b)
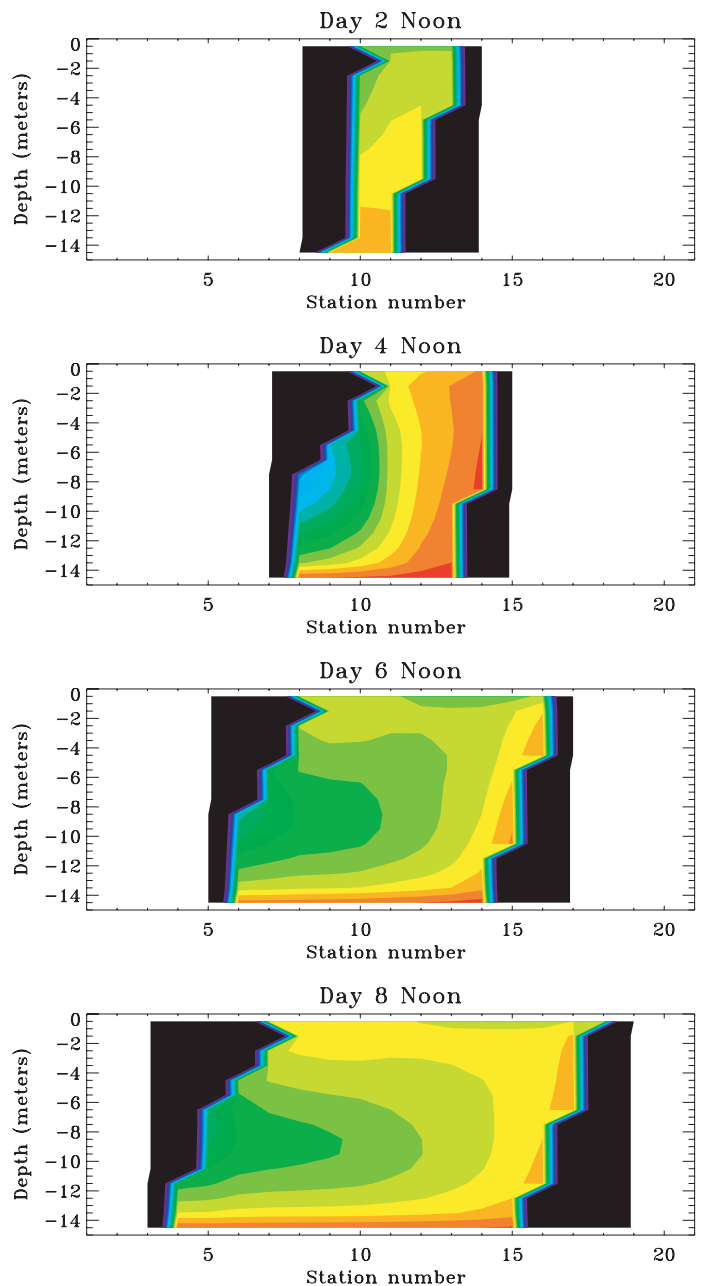

Day 10 Noon

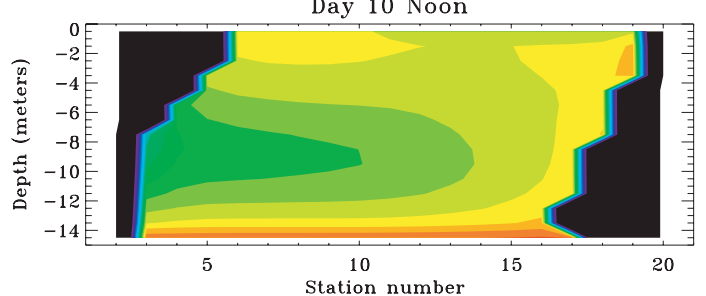

Station number
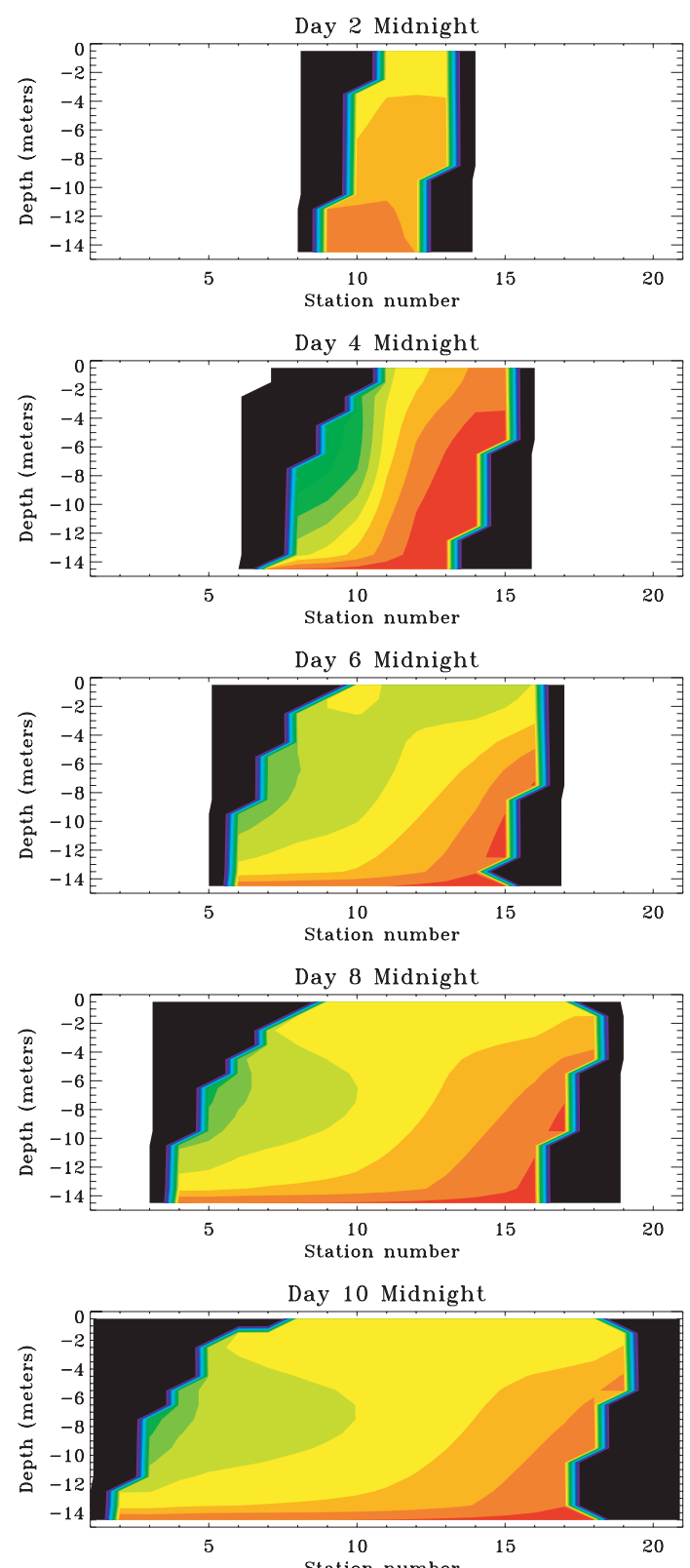

Station number

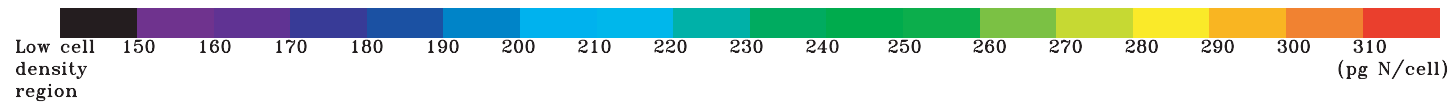

lated strong bottom aggregations in the other 2 cases discussed below. The present swimming rules in the model focus on migration control over the full water column and the refinement of the rules for a finer structure of vertical cell distribution within a nitrate source may be needed in the future when relevant field and laboratory observations become available.

Since the population aggregates at the surface, with most cells distributed within the plume depth in the upper portion of the water column during both the day and night, the population is advected to the right in the domain (Fig. 3a). The population is dispersed a little by the shear, but it keeps a very coherent structure.

According to the modeled migratory behavior and the vertical velocity profile, the low-carbon, lownitrogen new daughter cells in this case aggregate at the surface and are advected to the right with a higher water speed than the cells below the surface. When these cells achieve the high-carbon, high-nitrogen levels at the surface, descend, and finally aggregate at the base of the plume, they are located in a horizontal position a little to the right of the original horizontal posi- 
a) Surface Plume Case

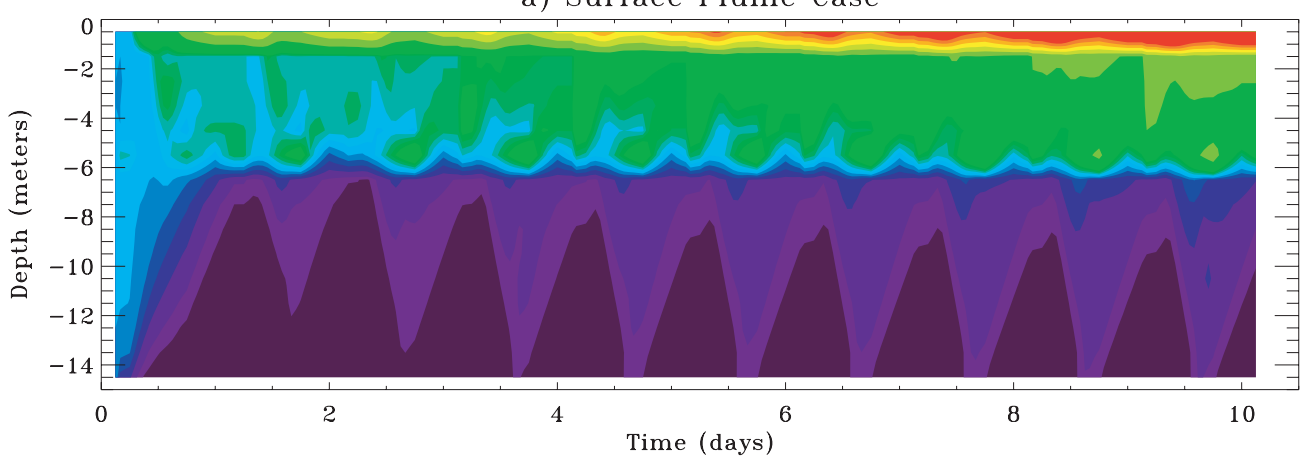

b) Bottom Plume Case

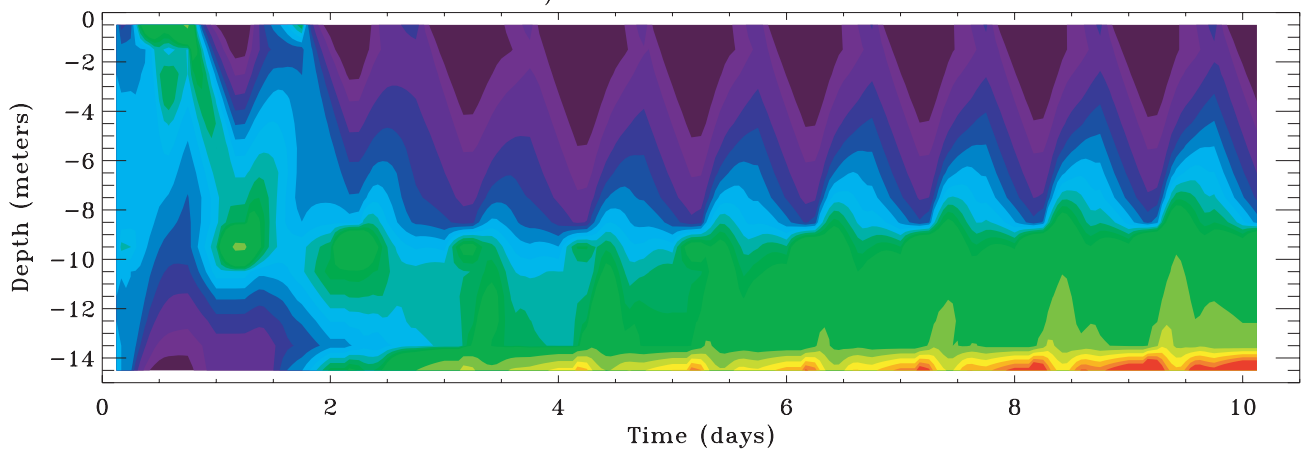

c) Uniform Water Column Case

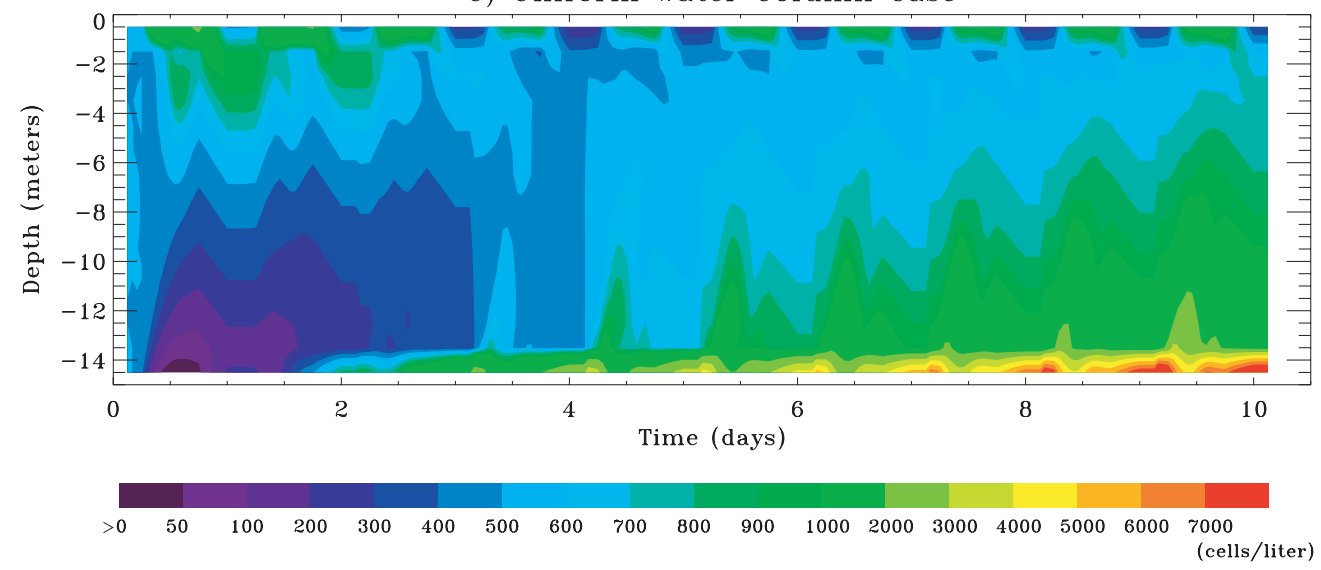

Fig. 7. Gymnodinium breve. Simulated vertical population distribution over $10 \mathrm{~d}$ period for all 3 cases. Cell concentration at any one depth is sum of the cell concentrations at that depth over all stations

tion where they started ascent. The interaction between the diel vertical migration and vertical velocity shear causes the horizontal location of the surface aggregation toward the right portion of the cell patch and the slow descending speed of high-carbon cells in the plume causes greater horizontal displacements of the cells. Hence, high carbon and high nitrogen concentrations are present around the base of the plume in the right portion of the cell patch and no highcarbon, high-nitrogen cells are distributed at the rear (left) end of the patches which are moving to the right.
Comparison between the vertical carbon and nitrogen distributions at noon and midnight on each day shows the upward spreading of the high-carbon, high-nitrogen band at the base of the plume. This is caused partly by the ascent of the nitrate-seeking cells between sunset and midnight and partly by the uptake of carbon and nitrogen between the 2 times. Note that the biochemical distribution figures (Figs. 4 to 6) are plotted on a per cell basis, and a high concentration region may not be the region with the highest biochemical content in the water. 
In the bottom plume case, low-carbon cells ascend from the bottom toward the surface during the day for higher light intensity (Figs. 3b \& 5a,b), and are advected to the left (at lower speeds than cells beneath them) if they remain in the lower portion of the water column or to the right if they enter the upper portion of the column. High-carbon cells (which are in the majority) follow the direction of the vertical nitrate gradient, and descend and aggregate at the bottom within the high nitrate concentration plume. Because of the high nitrate concentration within the bottom plume, the descending speed of the high-carbon cells is relatively low in the plume and thus some of these cells spread in the plume. The daily maximum cell aggregation at the bottom occurs around 04:00 h (according to the hourly model output), after the division of the majority of the reproducing cells and immediately before the lowcarbon cells ascend toward the surface (Fig. 7b). Be- (8a)
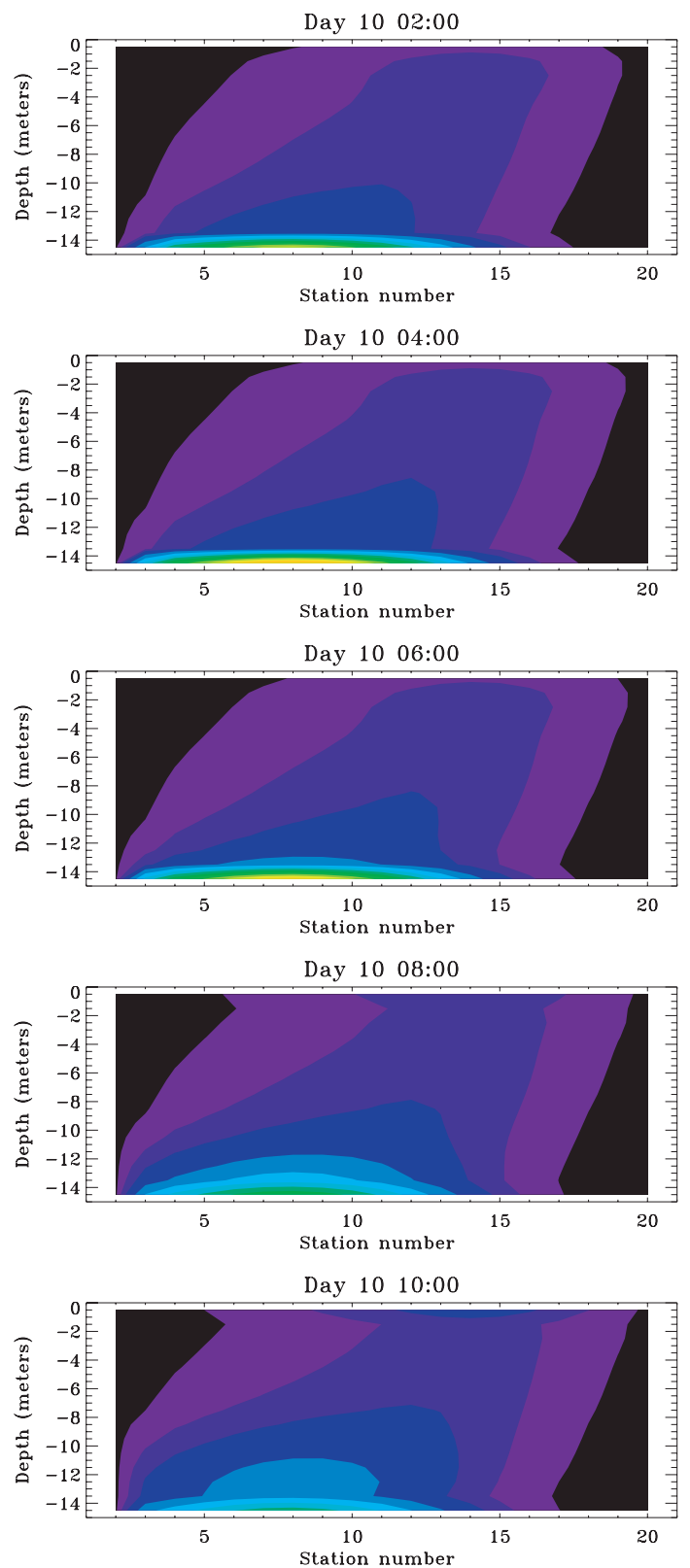
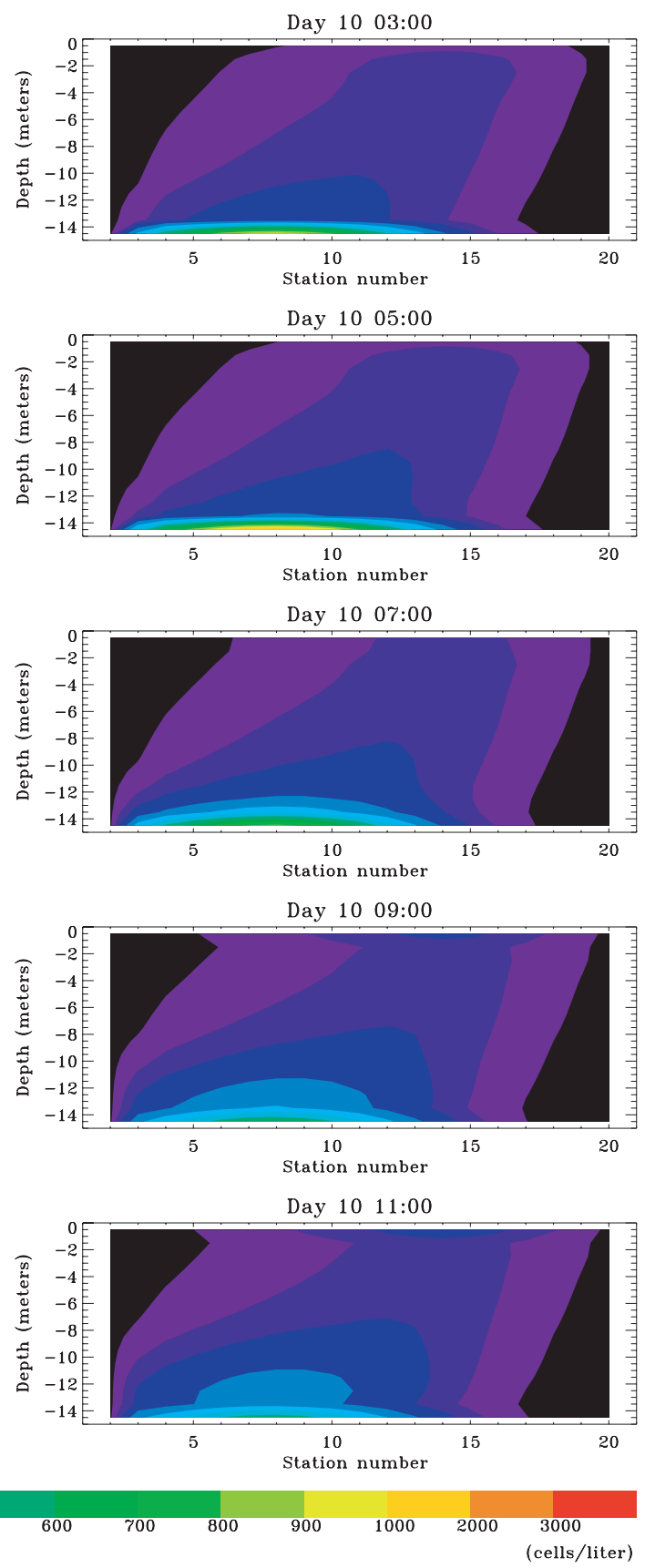

Fig. 8. Gymnodinium breve. Simulated hourly distribution in $x$-z plane from 02:00 through 11:00 h on Day 10 of a $10 \mathrm{~d}$ period in uniform water column: (a) population, (b) average internal carbon concentration, and (c) average internal nitrogen concentration 
(8b)
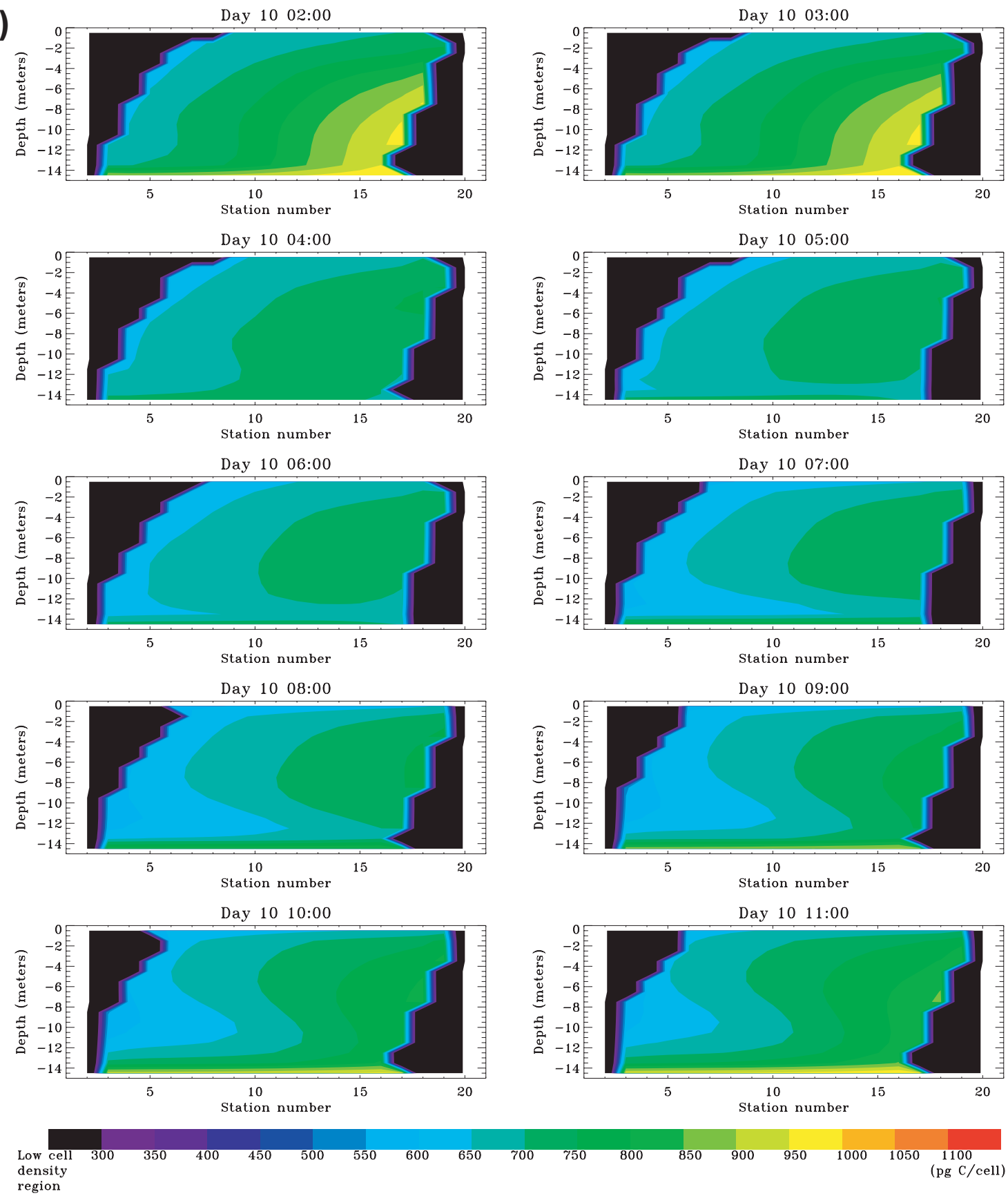

100 density

cause the population aggregates near the bottom, with most of the cells within the bottom plume where the water motion is to the left with a speed decreasing upward, the population is advected to the left in the domain. The population also keeps a coherent structure over the $10 \mathrm{~d}$ period. The daily minimum bottom aggregation is around noon. A more detailed explanation of the vertical population distribution in a similar vertical nitrate distribution condition (i.e. the persistent upwelling scenario) can be found in Liu et al. (2001).
In this bottom plume case, the high-carbon, high-nitrogen cells are distributed at the bottom (Fig. 5). In the lower-rear (right) portion of the cell patch, the high biochemical concentrations extend upward from the bottom into the water column. This is because the number of high-carbon, high-nitrogen cells descending into this region from above is close to or even greater than the number of the lower-carbon, lower-nitrogen cells present in this region; in the central lower region where the center of the aggregation is located, the lower- 
$(8 c)$
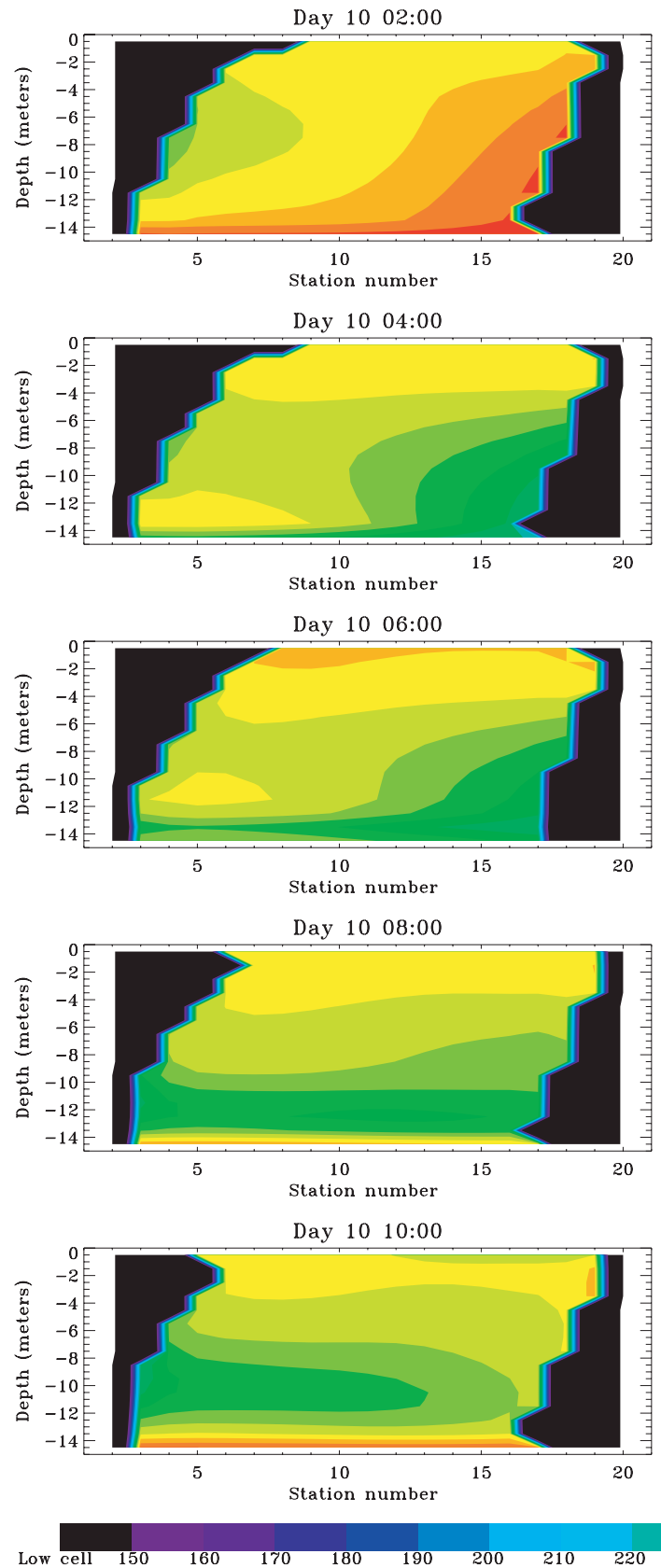

Low cell region

carbon, lower-nitrogen cells present just above the bottom aggregation greatly outnumber the high-carbon, high-nitrogen cells descending from above, and in the left-portion of the patch no cells descend from above.

In the uniform water column case (Figs. 3c \& 6), in which the nitrate concentration is high everywhere in the water column, more cells are distributed over the whole water column than in the other 2 cases. The weak surface aggregation during the day is caused by the ascending low-carbon new daughter cells. Com-
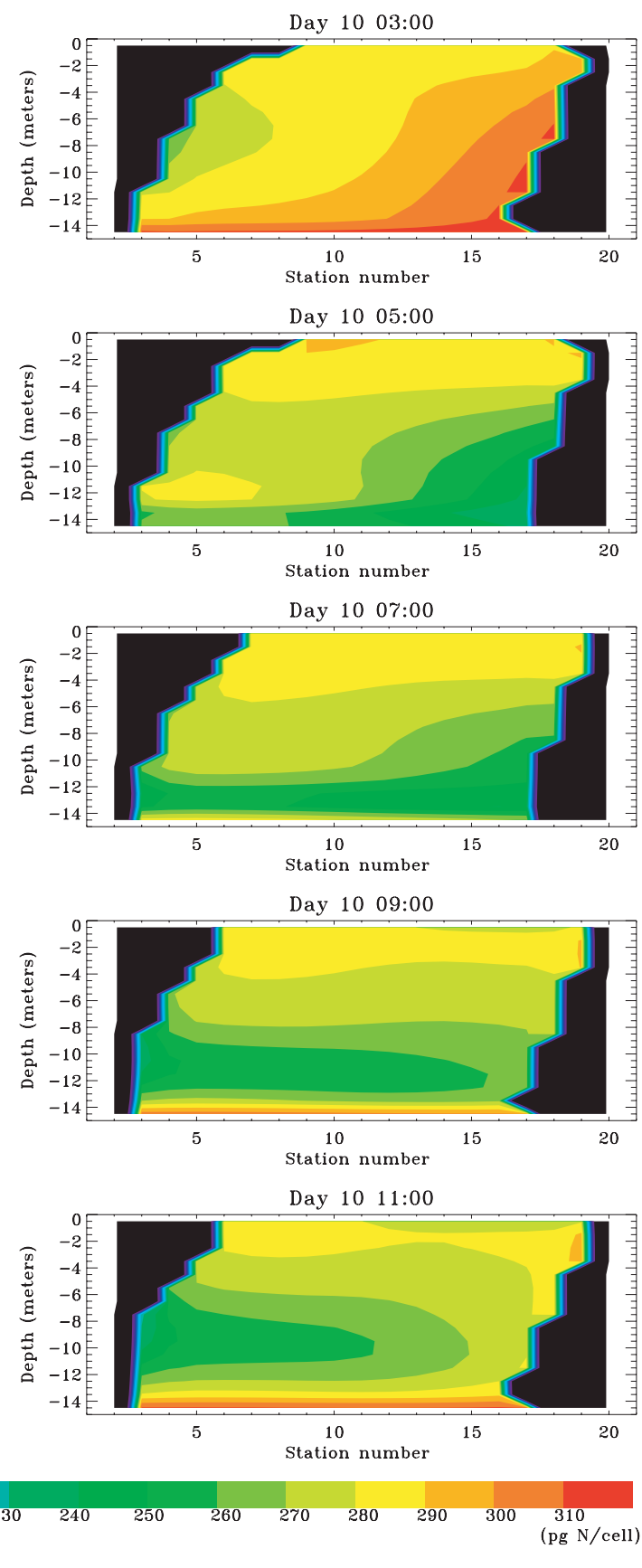

pared to the bottom plume case, the low-carbon cells in this case can reach the surface because of their faster ascending speed and slower descending speed associated with the high ambient nitrate concentration in the upper portion of the water column. However, most of the high-carbon, high-nitrogen cells aggregate at the bottom. Thus, the center of the population is advected to the left in the domain. The population is still in a coherent structure but horizontal dispersion is greater than in the other 2 cases. 
The biochemical distributions in the uniform water column case (Fig. 6) are different from the distributions in the other 2 cases (Figs. 4 \& 5). Although the reasons for the biochemical distributions are generally similar to that for the bottom plume case, the distribution is unlike the distributions in the bottom plume case in many portions of the cell patch because the population in this case is dispersed to a much greater extent. The reasons for the presence of the highest biochemical concentrations at the bottom and in the right portion of the cell patch are the same as the reasons for the similar distribution pattern in the bottom plume case. However, the greater extent of the vertical cell distribution in the uniform water column case causes the high biochemical concentration region to extend farther into the water column from the bottom in the right portion of the cell patch than in the bottom plume case. Compared to the bottom plume case, the uniform high nitrate concentration throughout the water column, causes the region containing the high-carbon, highnitrogen cells to extend higher into the water column. A tongue-shaped, low-carbon, low-nitrogen structure extending from the low-carbon, low-nitrogen region on the left toward the high-carbon, high-nitrogen region on the right is due to the upward migration of the new low biochemical content daughter cells that are produced within the bottom aggregation region (mostly around 03:00 h) in the reproduction period.

To illustrate this dynamic tongue-shaped structure more clearly, Fig. 8 shows the simulated spatial distributions of cells, average internal carbon, and average internal nitrogen concentrations in the $x-Z$ plane for 10 consecutive hours on the last day (Day 10) from 02:00 to 11:00 $\mathrm{h}$ for the uniform water column case. In this figure, the differences in the concentrations between 03:00 and 04:00 $\mathrm{h}$ demonstrate that reproduction causes an increase in cell concentration in the domain, especially in the bottom aggregation region, and dramatic corresponding decreases in the average biochemical concentrations. After the reproduction period, a low-carbon, low-nitrogen band appears initially right at the bottom through the domain and then continuously moves upward and separates from the bottom at 06:00 h. It is obvious that this band is formed by the new low-carbon, low-nitrogen daughter cells produced at the bottom, and that the upward movement of the band is caused by the ascent of these cells while the high-carbon old cells remain on the bottom. While the band moves upward during the day, high-carbon cells in the water column continuously descend and aggregate at the bottom to increase the carbon and nitrogen concentrations at the bottom. Later, the horizontal band becomes a tongueshaped structure because the descent of high-carbon, high-nitrogen cells from above increases the bio- chemical concentrations in the right portion of the cell patch more quickly than in the middle portion due to the difference in the cell concentration between regions, as discussed earlier. It is apparent that the interaction between the diel vertical migration, vertical velocity shear, and vertical nitrate distribution induces this diel, vertical, circulation-like pattern in spatial internal biochemical distributions.

The shift of the highest biochemical concentration region from the left portion to the right portion of the patch from Day 3 to Day 4 in all 3 cases is caused by the significant cell division starting on Day 4 (Fig. 2). It can be seen in Figs. 4 to 6 that the overall average internal carbon and nitrogen concentrations in the whole cell patch are lower at noon than at the previous midnight each day. This is the consequence of cell reproduction in the early morning and the uptake of carbon and nitrogen during the day. The difference in the average internal carbon and nitrogen concentration between 03:00 and 04:00 h on Day 10 for the uniform water column case (Fig. 8), discussed above, illustrates the effect of reproduction on the spatial distributions of the internal carbon and nitrogen. For succinctness, corresponding figures for the other 2 cases are not shown.

Figs. $5 \& 6$ show that the spatial separation of poorer and richer cells is least intensive in the surface plume case and most intensive in the uniform water column case. The difference is related to the way that the light and nitrogen swimming rules interact with the surface and bottom interfaces in the different cases.

Fig. 9 shows the horizontal advection and dispersion of the population over the $10 \mathrm{~d}$ period for the 3 cases. The curves in the Fig. 9 represent the percentage of the population to the left of the curves; the 5 curves plotted from left to right demonstrate the evolution of the boundaries to the left of which 5, 25, 50, 75 and $95 \%$ of the population, respectively, are located. The center of the population is indicated by the $50 \%$ curve; the horizontal span of $50 \%$ of the population spreading from the center of the population is within the 25 and $75 \%$ curves and the span of $90 \%$ of the population is within the 5 and $95 \%$ curves. The simulations illustrate that the advection of a Gymnodinium breve population by currents with vertical shear becomes much more complex when cells are capable of vertical migration and especially when the cells' migratory behavior acclimates to the external nutrient and light conditions. The advective direction of the center of the population relative to the model domain is determined by the vertical location of the population aggregation: the population in the surface plume case moves to the right, in the bottom plume case to the left, and in the uniform water column case also to the left. Note that in the present model the model domain with the population within it is moving onshore (i.e. to the right in Fig. 9), 
with a vertically uniform and constant mean onshore velocity, which is not specified and can be strong or weak.

After the $10 \mathrm{~d}$ simulation, the surface plume case has the most coherent patch, with $90 \%$ of the population spreading over ca. $6.67 \mathrm{~km}$, (stations are $1 \mathrm{~km}$ apart) and the greatest advective displacement of the center of the population (about $5.24 \mathrm{~km}$; Fig. 9a). This case displays the strongest mechanism for population aggregation. The uniform water column case has the most dispersive population distribution among all 3 cases. The patch spreads out in both directions, with $90 \%$ of the population covering a horizontal span of about $12.38 \mathrm{~km}$, and is elongated and tilted by the vertical shear. The bottom aggregation causes the center of the population to be advected to the left over a distance about $1.90 \mathrm{~km}$ (Fig. 9c); this case has the weakest mechanism for population aggregation. The bottom plume case has a final cell patch with $90 \%$ of the population spreading over about $7.62 \mathrm{~km}$ and an advective displacement of the center of the population of ca. $4.29 \mathrm{~km}$ (Fig. 9a).

Although the population persistently aggregates either at the surface or at the bottom, the cells' diel vertical migration continues to change the cells that contribute to the aggregation over time. Cells initially located at the surface (or at the bottom) of the water column at the leading edge of the cell patch may descend (or ascend) into a depth with slower current velocity or even with velocity in the opposite direction. These cells or their descendants may ascend (descend) at a later time to move back to their original depths in the rear portion or tail region of the cell patch. Thus, the interaction of continuous cell vertical migration and continuous horizontal advection by the sheared flow causes the population to be advected at a slower speed than in the situation where all the non-migrating cells simply accumulate at the surface or at the bottom. Furthermore, this type of interaction reveals a possible field sampling problem, if the cells that aggregate at a given location in a patch change from day to day as individual cells cycle within the patch. With the vertical resolution of our present model, a water parcel staying in the surface layer (centered at $-0.5 \mathrm{~m}$ ) or in the bottom layer (centered at $-14.5 \mathrm{~m}$ ) could be advected $8.04 \mathrm{~km}$ from its initial horizontal location; however, the center of the population only moves about $+5.24,-4.29$, and $-1.90 \mathrm{~km}$ for the surface plume, bottom plume, and uniform water column cases, respectively (Fig. 9). In the first 2 cases $90 \%$ of the population moved out of the initial station (Stn 11) during the $10 \mathrm{~d}$ simulation period (Fig. 9a,b), while in the last case the center of the population hardly moved at all over the $10 \mathrm{~d}$ period.

\section{Conclusions}

The simulations clearly demonstrated that although the vertical shear tends to disperse the population, Gymnodinium breve's vertical migratory behavior tends to maintain a coherent structure of population distribution. In the presence of vertical shear in the horizontal current, the horizontal advection and dispersion
Fig. 9. Gymnodinium breve. Simulated horizontal population, advection and dispersion over $10 \mathrm{~d}$ period in (a) surface plume, (b) bottom plume, and (c) uniform water column 
of a G. breve population in the region are significantly controlled by the vertical nitrogen distribution as a consequence of the acclimation of $G$. breve migratory behavior to environmental conditions including nitrogen and light. The smaller the depth range of the high nitrogen concentration region in a water column, the more coherent the patch of $G$. breve cells. Furthermore, the simulation results suggest that the concurrence of multiple nitrogen sources in a water column should cause a population to segregate into different subpopulations according to the number of the nitrogen sources and their depths.

Different dinoflagellate species with different migratory behaviors may display different types of interaction between vertical migration, vertical shear in the current, and nitrogen condition.

Vertical shear-induced segregation of cells in a population with different internal biochemical concentrations, as suggested by Kamykowski et al. (1998a), may produce quantized subpopulations in the natural environment. The vertical shear structures and nutrient conditions which may cause this type of segregation were not considered in our present simulations, and remain to be investigated.

The results also suggest that temporal studies of Gymnodinium breve field populations may benefit from a consideration of discrete aggregations as a unit. Individual cells may cycle through the aggregation in response to the interactions between physical forcing and vertical migration. A sampling design that ignores this cycling may provide only a limited view of the population dynamics in the aggregation. For example, cell division may not be observed because it is predominantly occurring in a different part of the aggregation.

This numerical investigation of the influence of the vertical velocity shear on Gymnodinium breve population dynamics only touches upon a small aspect of the whole issue of the influence of the physical processes. For further investigation of the influence of physical processes such as upwelling, fronts and turbulent mixing on the west Florida shelf on G. breve population dynamics, and particularly, its red tide development, a 3-dimensional shelf-circulation model should be incorporated into the $G$. breve population dynamics model.

Acknowledgements. We thank Gary Kirkpatrick, Robert E. Reed, and Edward J. Milligan for valuable comments and technical support. This work was supported by ECOHAB: Florida grant funded by the Florida Department of Environmental Protection, NSF grant OCE-95-03253, and NASA grant NAG56586.

\section{LITERATURE CITED}

Blasco D (1978) Observations on the diel migration of marine dinoflagellates off the Baja California coast. Mar Biol 46:41-47
Cullen JJ, Horrigan SG (1981) Effects of nitrate on the diurnal vertical migration, carbon to nitrogen ratio, and the photosynthetic capacity of the dinoflagellate Gymnodinium splendens. Mar Biol 62:81-89

Dahl E, Tangen K (1993) 25 years experience with Gyrodinium aureolum in Norwegian waters. In: Smayda TJ, Shimizu Y (eds) Toxic phytoplankton blooms in the sea. Elsevier, Amsterdam, p 15-22

Donaghay PL, Osborn TR (1997) Toward a theory of biological-physical control of harmful algal bloom dynamics and impacts. Limnol Oceanogr 42:1297-1305

Franks PJS (1997) Models of harmful algal blooms. Limnol Oceanogr 42:1273-1282

Franks PJS, Anderson DM (1992) Alongshore transport of a toxic phytoplankton bloom in a buoyancy current: Alexandrium tamarense in the Gulf of Maine. Mar Biol 112: 153-164

Heil C (1986) Vertical migration of Ptychodiscus breve (Davis) Steidinger. MS thesis, University of South Florida, St. Petersburg, FL

Janowitz GS, Kamykowski D (1999) An expanded Eulerian model of phytoplankton environmental response. Ecol Model 118:237-247

Kamykowski D (1974) Possible interactions between phytoplankton and semidiurnal internal tides. J Mar Res 32:67-89

Kamykowski D (1995) Trajectories of autotrophic marine dinoflagellates. J Phycol 31:200-208

Kamykowski D, McCollum SA (1986) The temperature acclimatized swimming speed of selected marine dinoflagellates. J Plankton Res 8: 275-287

Kamykowski D, Yamazaki H (1997) A study of metabolisminfluenced orientation in the diel vertical migration of marine dinoflagellates. Limnol Oceanogr 42:1189-1202

Kamykowski D, Milligan EJ, Reed RE (1998a) Biochemical relationships with the orientation of the autotrophic dinoflagellate, Gymnodinium breve, under nutrient-saturated conditions. Mar Ecol Prog Ser 167:105-117

Kamykowski D, Yamazaki H, Yamazaki AK, Kirkpatrick GJ (1998b) A comparison of how different orientation behaviors influence dinoflagellete trajectories and photoresponses in turbulent water columns. In: Anderson DM, Cembella AD, Hallegraeff GM (eds) Physiological ecology of harmful algal blooms. Springer-Verlag, Berlin, p 581-599

Levandowsky M, Kaneta P (1987) Behavior in dinoflagellates. In: Taylor FJR (ed) The biology of dinoflagellates. Blackwell Scientific, Oxford, p 360-397

Liu G, Janowitz GS, Kamykowski D (2001) The influence of environmental nutrient conditions on Gymnodinium breve (Dinophyceae) population dynamics: a numerical study. Mar Ecol Prog Ser 213:13-37

Mackas DL, Denman KL, Abbott MR (1985) Plankton patchiness: biology in the physical vernacullar. Bull Mar Sci 37: 652-674

Steidinger KA (1973) Phytoplankton ecology: a conceptual review based on eastern Gulf of Mexico research. Crit Rev Microbiol 3:49-67

Steidinger KA (1975) Implications of dinoflagellate life cycles on initiation of Gymnodinium breve red tides. Environ Lett 9:129-139

Steidinger KA, Haddad K (1981) Biological and hydrographic aspects of red tides. BioScience 31:814-819

Tester PA, Steidinger KA (1997) Gymnodinium breve red tide blooms: initiation, transport, and consequences of surface circulation. Limnol Oceangr 42:1039-1051

Walsh JJ, Kelley JC, Whitledge TE, MacIsacc JJ (1974) Spin-up of the Baja California upwelling ecosystem. Limnol Oceanogr 19:553-572 